\title{
HUMAN CAPITAL PORTFOLIOS *
}

\author{
Pedro Silos ${ }^{\dagger} \quad$ Eric Smith ${ }^{\ddagger}$
}

January 2013

\begin{abstract}
This paper assesses the trade-off between acquiring specialized skills targeted for a particular occupation and acquiring a package of skills that diversifies risk across occupations. Individual-level data on college credits across subjects and labor market dynamics reveal that diversification generates higher income for individuals who switch occupations whereas specialization benefits those who stick with one type of job. A human capital portfolio choice problem featuring skills, abilities, and uncertain labor outcomes replicates this general pattern and generates a sizable amount of inequality. Policy experiments illustrate that forced specialization generates lower average income growth and lower turnover, but also lower inequality.
\end{abstract}

JEL codes: J24, E24

Keywords: Human Capital, Occupational Choice, Income Inequality

\footnotetext{
${ }^{*}$ We have received helpful comments from seminar participants at the Atlanta Fed, the Philadelphia Fed and the Universities of Essex, Iowa, Hawaii-Manoa, Konstanz, North Carolina, Southern California, Toronto, the Canadian Macroeconomics Study Group, the NBER Macro Perspectives Group, and the Midwest Macroeconomics Meetings. We thank H. He, L. Hendricks, G. Kambourov, B. Kuruscu, G. Moscarini, M. Pergamit, L. Pistaferri, T. Schoellman, R. Shimer, G. Vandenbroucke, R. Wolthoff, and especially G. Violante for useful suggestions. This research uses restricted-access data from the National Center for Education Statistics (NCES) and we thank its staff for their help. The views expressed here are those of the authors and cannot be attributed to the Federal Reserve Bank of Atlanta or the Federal Reserve System.

${ }^{\dagger}$ Federal Reserve Bank of Atlanta. 1000 Peachtree St. NE, Atlanta, GA 30309, pedro.silos@atl.frb.org

‡University of Essex. Department of Economics, Wivenhoe Park, Colchester, Essex CO4 3SQ, esmith@essex.ac.uk
} 


\section{Introduction}

Every occupation requires a different set of skills. Conversely, many skills are useful, to different degrees, in a wide variety of professions. A literary editor, a corporate lawyer and a marine biologist all apply related skills involving reading, writing and arithmetic but in different amounts. Moreover, some occupations appear to more heavily emphasize a subset of particular skills whereas other professions more or less weigh skills evenly. Engineers, for instance, are likely to be more specialized than sales reps.

Individuals acquire many of these different skills before entering the workforce at which point they face the uncertainty of settling on a trade or profession. A college graduate may, for example, study music but not make it as a musician. Knowing these risks, students will want to balance their efforts in case their initial target occupation does not work out. They will want to choose the composition of their courses to acquire a set of skills based on inherent abilities and on their expected payoffs in prospective professions.

To help assess the impact of occupational matching uncertainty on the range of acquired skills and on earnings dynamics, this paper first establishes panel data evidence linking labor market outcomes with the fit of an individual's acquired skill set in their chosen occupation. The paper then constructs, estimates and assesses a human capital portfolio choice problem for individuals facing an uncertain labor market.

A precise economic framework is spelled out to discern underlying trade-offs. Students who vary in both their innate abilities to learn and in their potential in distinct jobs will choose their set of skills based on these differences. Coupled with labor market uncertainty, these unobservables will also generate idiosyncratic labor market outcomes. As a result, students targeting the same first occupation are likely to acquire different portfolios of skills to use in their intended job as well as in their back-up plan. The skills portfolio decision problem put forward in this paper is used to identify the roles these different unobserved factors play from detailed information on human capital choices and labour market histories.

The framework adopted here assumes that agents know from the outset their abili- 
ties to acquire imperfectly substitutable skills. They also receive a signal of their potential 'fit' or prospects in a number of occupations. Given this personal information as well as the expected skill payoffs in each profession, agents choose their human capital portfolio, that is, the amount of each skill they acquire. After investing in training, individuals enter their preferred or primary occupation.

Each occupation values all human capital types but to a different degree. Human capital, expected productivity and the fitness signal in that profession determine initial pay. As employment continues in an occupation, an agent's true productivity is at some point fully revealed. Those with good realizations stay in that job permanently and earn their true productivity. Those with poor draws try their second best option again without initially knowing their true quality in the new job. The process repeats itself until the individual settles in an occupation.

This framework reveals a tension between specialization and diversity. ${ }^{1}$ Innate talents and idiosyncratic signals of potential provide an incentive for individuals to specialize by acquiring skills that reflect their personal circumstances. Students rationally pursue those subjects in which they show promise and talent. In contrast, the risk of low productivity draws in each occupation provides an incentive to acquire a more widely applicable portfolio of human capital skills.

Using the 1980 High School and Beyond (HS\&B) survey which has detailed information from post-secondary transcripts, we quantitatively assess this trade-off between specialization and diversity. For the most part, students in the US begin to specialize after high school as they choose post-secondary institutions and then majors. Minors and elective courses further allow students to tailor a portfolio of skills based on their innate abilities and their career aspirations. Transcripts in HS\&B thus give empirical measures of human capital portfolios that are used to find the underlying parameters of the skill distribution, the signals of occupational fit and the technological skill use by occupations.

\footnotetext{
${ }^{1}$ This familiar tension has long been acknowledged and dates back to Smith (1776).
} 
The HS\&B survey also contains labor market histories for individuals' early careers - up to around the age of thirty - that link human capital portfolios to individual earnings and labor market dynamics. Looking at the pattern of earnings, the estimated model performs well. The estimates of the model are based primarily on matching the observed human capital portfolios and the pattern of occupational switching. None the less, simulated data found using these estimates mirror the observed relationship between portfolio concentration, career switches and earnings.

Targeting and hedging in the portfolios appear to affect earnings in similar ways in both the simulated and actual data. The model implies that the realized fit in a profession translates into productivity and hence pay. Agents with more targeted portfolios who remain in an early career choice experience higher earnings and earnings growth. Workers with more versatile portfolios who switch earn more than switchers with specialized portfolios. Those who settle early, that is those who realize better first draws, receive high and rapid growth in earnings. Those who switch encounter an immediate earnings decline. Similarly, those who settle early tend to earn more than those who try several professions. Occupational mobility also declines and the earnings distribution fans out over time.

As the model and data are close along several dimensions of interest, it is natural to consider policies that shape the hedging decision. We find that a European-style education system characterized by mandatory specialization in an occupation generates a lower degree of turnover, lower earnings growth, and lower variance of $(\log )$ earnings. An alternative system that allows for more breadth and hedging opportunities (the US higher education system) trades off higher growth rates in earnings for a more unequal income distribution.

These results extend the human capital literature with uncertainty. The early human capital literature developed to understand earnings over the life-cycle, Becker (1994) or Ben-Porath (1967), focused on investments in homogeneous human capital. Subsequent contributions added uncertainty about future rewards. Levhari and Weiss 
(1974) and Altonji (1993) are two prominent examples. More recently, Wasmer (2006) as well as Gervais, Livshits, and Meh (2008) study from a theoretical perspective the trade-off between (more risky) specific and general human capital during periods of aggregate "turbulence". ${ }^{2}$

A parallel literature considers multi-dimensional endowments of abilities which determine self-selection of individuals into different sectors, as in Heckman and Sedlacek (1985) and Heckman and Sedlacek (1990), or occupations, as in Willis (1987). These studies formalize the static Roy (1951) model of comparative advantage and occupation selection. ${ }^{3}$ Keane and Wolpin (1997) use a dynamic Roy framework to estimate a structural model of a joint schooling and occupational choice decision. In the Keane and Wolpin's framework, individuals have an initial endowment of occupationspecific abilities (including an ability level to accumulate human capital) and they control their schooling and occupational choice to maximize lifetime earnings. ${ }^{4}$ See also Gathmann and Schönberg (2010) and Yamaguchi (2012) who extend that literature by redefining occupations as bundles of tasks and exploring the pattern of mobility of individuals across occupations. Employing a similar framework Sanders (2011) analyzes the interaction between learning about one's abilities and occupations transitions. Finally, Arcidiacono (2004), Kinsler and Pavan (2012) study to what degree the different observed rates of return of alternative majors can be explained by selection into majors and jobs. The focus of these studies is not an optimal portfolio choice motivated by uncertainty about occupational fit and its implications for earnings dynamics. ${ }^{5}$

Other papers on occupational and job turnover emphasize the importance of learn-

\footnotetext{
${ }^{2}$ An empirical literature has developed to evaluate the degree of mismatch between occupations and the choice of major or field. Malamud (2010) and Robst (2007) are two examples in this extensive literature. Malamud examines the relationship between the timing of the choice of field and the likelihood of working in an unrelated occupation. Robst explores the wage effects of the distance between field of study and occupation.

${ }^{3}$ Lazear (2009) and Schoellman (2010) are more recent examples of works that share some elements with that earlier literature.

${ }^{4}$ Other studies in the literature of occupational choice include Sullivan (2010) and James (2011).

${ }^{5}$ For an overview of studies on human capital with an emphasis on its multi-dimensional nature, the reader is referred to Sanders and Taber (2012).
} 
ing through the acquisition of information after individuals enter the labor market. Jovanovic (1979) and Miller (1984) follow up and formalize to some extent the narrative approach of Stigler (1962). Miller's model of the labor market is close to the one employed here, although he abstracts from human capital investment. The distinguishing feature of Miller's framework is the sequential revelation of information as individuals try new occupations or careers which generates a trade-off between exploring new occupations and exploiting the current one. More recent work includes Antonovics and Golan (2012) who study the tradeoff between information and wages in a model of occupational choice. They use a model of job choice to infer how much information different occupations reveal about workers' productivities. ${ }^{6}$

Finally, a substantial literature studies the nature of shocks that individuals experience over the life-cycle and the cross sectional inequality in earnings that these shocks generate. Huggett, Ventura, and Yaron (2011) investigate whether shocks experienced over the life cycle or differences established early in life determine the bulk of crosssectional earnings inequality. Kambourov and Manovskii (2009) explore the link between the rise in occupational mobility and the rise in earnings inequality. That link is also central to our work here, so much so that restrictions to the choice of human capital in the model generate a lower degree of occupational mobility and a more equal distribution of earnings. Lifting those restrictions overturns the results.

This paper contributes directly to these literatures by considering the choice of the optimal mix of skills under occupational uncertainty. It examines the interaction of that choice with the information revealed as labor market histories unravel and their consequent effect on occupational transitions. The framework and empirical evidence presented provide a new way to analyze the dynamics of occupational switching, labor earnings and the accompanying inequality that arises during the early years of

\footnotetext{
${ }^{6} \mathrm{Neal}$ (1999) studies workers' decisions in the early stages of their labor market careers emphasizing the two-stage nature of their search strategy. Individuals first settle on an occupation or career path. After this decision has been made, they start shopping for better jobs. This two-dimensional search leads to a large amount of turnover among the young explored in detail by Topel and Ward (1992).
} 
individuals' life-cycles.

\section{Preliminary Evidence}

\subsection{Data}

This section examines the observed empirical relationship between portfolios of human capital acquired through formal post-secondary education and the dynamics of labor market earnings observed in the 1980 Sophomore Cohort of the High School and Beyond (HS\&B) survey. This panel dataset contains a rare, if not unique, combination of information on post-HS credits obtained in different areas of study as well as information on post-training labor market histories. ${ }^{7}$

The HS\&B survey, conducted by the National Center for Education Statistics, interviewed a nationally representative sample of high school students who were sophomores in 1980 once every two years between 1980 and 1986 and once again in 1992. For each student/worker, these interviews recorded labor market outcomes in employment, earnings and occupation that individuals experienced from the first year after graduation until the last year of the panel (1991).

The labor market data from the survey were merged with information about postsecondary credits in different fields found in the Post-Secondary Education Data System (PETS). PETS contains institutional transcripts from all post-secondary institutions attended for a sub-sample of students present in the survey. These high quality, administrative data provide the measures of human capital diversification used here.

The initial HS\&B survey contains 14,825 students. A sub-sample of 8,325 students had their transcripts encoded. Most students, however, never earned an advanced degree. To focus on the make-up of portfolios rather than on differences in the levels of human capital acquisition, the sample is further restricted to those students who

\footnotetext{
${ }^{7}$ Given that we do not observed the amount of hours worked, throughout the study the terms earnings, wage and income are all used to denote the same concept: compensation for labor in a given period.
} 
earned at least an associates degree, but no more than a one-year masters degree. This restriction yields a sample of about 1,360 students.

Graduation dates (years) differ across students as do the initial dates and length of observed labor market histories. For histories to be sufficiently long to generate at least two years of labor market data for all individuals, we dropped students who graduated in 1988 or later. In the sample, roughly $70 \%$ of students graduated from higher education in 1988 or before. Further cleaning of the data yields a final sample of 920 students. $^{8}$ The Appendix provides a step-by-step description of the cleaning process as well as other data-related issues including details on the construction of human capital portfolios.

Human capital portfolios, calculated from transcript credits, contain three areas or components of study. PETS groups credits into (i) quantitative and scientific courses including engineering and computer science, (ii) humanities including history, foreign languages, fine and performing arts, ${ }^{9}$ and (iii) social science, business and communications. Credits in sub-categories (e.g. in fields such as biology, literature, sociology and so on) are available but not used. Using these more refined data not only drastically increases computational complexity, but also lowers the reliability of classification given the widespread existence of overlapping fields. Raw credits are weighted by a student's GPA (a standard measure of performance) in a particular area of study. ${ }^{10}$

Given (weighted) credits in each area or type of human capital $k=1, \ldots K$, the weights in the human capital portfolio of an individual $i$ readily follow as:

$$
\omega_{i, k}=\frac{\text { Credits }_{i, k}}{\sum_{j=1}^{K} \text { Credits }_{i, j}},
$$

where $K=3$. Table 1 displays these portfolio weights by occupation and overall across

\footnotetext{
${ }^{8}$ Due to the confidential nature of the data we must report all sample sizes rounded to the nearest ten whenever we are reporting a statistic.

${ }^{9}$ The PET data report figures separately for fine and performing arts. These figures are small and therefore combined with humanities in this study

${ }^{10}$ Using unweighted credits does not materially affect this analysis.
} 
the population. For each broad occupation category, the table displays the mean and the standard deviation of the distribution, across individuals, of the weights in each of the three human capital types.

Table 1 reveals substantial variation in the average human capital investments across occupations. The mean weight on humanities varies from fairly low values in Engineers (0.10) and Computer Related Technicians (0.14), to values of roughly half for Professional of the Arts. It is not surprising that Engineers have the highest mean weight in quantitative human capital (0.76), whereas this area of study represents barely $13 \%$ of the portfolios of Professionals of the Arts. Business owners and sales professionals have the highest shares of business and communications human capital, allocating about half of total credits on average, to this component.

Substantial variation also appears across portfolios within particular occupations, although the extent of within group variation in portfolios differs considerably. Engineers appear more homogeneous than Computer Related Technicians (Tech. Comp) or Medical Professionals (Prof.Medical). The standard deviation of their quantitative human capital weight is only 0.15 which produces a relatively small coefficient of variation. In contrast, the average weight in the quantitative area for Computer Related Technicians is somewhat smaller but the standard deviation nearly doubles.

Each student $i$ has a vector of human capital weights $\omega_{i, k}, k=1, \ldots, K$ in the $K=3$ components measuring the weight of skill of type $k$ in the overall portfolio. Viewed on its own, a skewed or balanced portfolio does not imply specialization or diversity of human capital investments. Students may opt for a uniform allocation of credits across fields to self-insure against shocks or because a particular occupation explicitly rewards balanced skills. To assess how well tailored an individual's acquired skill set is for a particular job, human capital investments must be viewed relative to a benchmark in that occupation.

There are several potential approaches to (as well as difficulties in) measuring how well suited a given set of acquired skills is to a particular occupation. This paper adopts 
a simple if crude measure. Suppose individual $i$ enters the labor market with human capital vector $\left(\omega_{i, 1}, \ldots, \omega_{i, K}\right)$ and first works in occupation $j$. The degree of hedging, $\delta$, for this particular individual - occupation pair is defined as the standard Euclidean distance in $\mathbb{R}^{K}$ that $i$ 's portfolio lies from the average portfolio observed in occupation $j:$

$$
\delta=\sqrt{\sum_{k=1}^{K}\left(\omega_{i, k}-\bar{\omega}_{j, k}\right)^{2}}
$$

where $\bar{\omega}_{j, k}$ denotes the typical (or average) portfolio for occupation $j$ observed in Table 1. A portfolio is tailored to a given occupation if that portfolio is "close" to the average portfolio of that occupation. Hedging is simply the distance between the portfolio weights and the typical portfolio of the first occupation after graduation.

The upper panel of Table 2 displays summary statistics describing the distribution for this measure as well as for five other relevant variables. $\log \left(Y_{91}\right)$ denotes (logged) earnings level observed in 1991, deflated by the CPI. $\Delta Y$ denotes the average annual growth rate of earnings for individuals as given by

$$
\Delta Y=e^{\log \left(Y_{91} / Y_{1}\right) /(T-1)}-1,
$$

where $Y_{1}$ denotes earnings (deflated for the appropriate year) in the first year after graduation and $T$ the time in years of individual labor market history. CRED denotes the total number of raw credits, and WCRED denotes credits weighted by GPA. Finally, STAY is an indicator variable that takes the value 1 if an individual never switches occupations and equals 0 otherwise. ${ }^{11}$

For this sample of students, the measure of hedging, $\delta$, displays considerable dispersion across individuals. The standard deviation is 0.16 for a variable that ranges between 0.018 and 0.848 , has a mean value of about 0.2 , and is bounded between zero and one.

\footnotetext{
11 The figures given in Table 2 correspond to a distribution of individuals truncated to eliminate the top and bottom $2 \%$ of average earnings growth.
} 
Real earnings growth per year in this sample averages about $7.7 \%$ with dispersion in line with other studies. Since retrospective surveys frequently suffer from a large degree of measurement error, we compared the earnings distribution for the years in our HS\&B sample to a similar sample from the Current Population Survey (CPS) and found that the two samples are similar. The Appendix reports the results of this comparison. ${ }^{12}$

As the majority of individuals in our sample achieve at most a bachelor's degree, it is not surprising that the median of the distribution for college credits (CRED) is 122 . Some high-achievers take over three hundred credit hours, but these are the exception as the standard deviation for this measure is only 27 . Finally, note that a little over $60 \%$ percent of individuals never switch occupations during the observed labor market histories.

The lower panel of Table 2 provides the raw correlations between these measures. Most of these correlations are significant as well as plausible. For instance, there is a strong (unconditional) negative relationship between earnings growth and remaining in the same occupation. The positive relationship between hedging and the number of credits taken hints at the possibility of individuals diversifying by adding credits rather than by transferring credits across areas. It seems sensible that the higher the degree of diversification, the higher the probability an individual switches occupations as reflected in the negative correlation between $\delta$ and STAY. On the other hand, note that the unconditional correlation between income growth and hedging is near zero and insignificant.

\footnotetext{
${ }^{12}$ It would be useful to control for hours worked and get a measure of earnings per unit of time but this is only partially feasible. Although the survey reports the monthly unemployment history (which we account for in our measures), it does not contain hours worked during the periods of employment or whether employment is part-time or full-time. As a result, some extreme values, for example, the minimum observed of -0.219 could be due to voluntary changes in hours worked because of health, family or other reasons. In what follows, it is very difficult to discriminate among possible causes for those fairly extreme earnings changes.
} 


\subsection{Empirical Regularities}

Interesting patterns emerge once one conditions on occupational switches. To investigate the empirical regularities beyond raw correlations, Table 3 presents OLS regression estimates linking the observed final earnings, $\log \left(Y_{91}\right)$, and the portfolio distance measure, $\delta .^{13}$

The first column of results reports regression coefficient estimates of $(\log )$ earnings with three further controls - the logarithm of the respondent's initial earnings $\log \left(Y_{1}\right){ }^{14}$ the logarithm of the total of credits, $\log (C R E D)$, and the individual's gender, SEX. All four variables' coefficients are significant with the expected sign. On average, male earnings are higher than women's earnings. Individuals with more credits also experience higher income. The coefficient on initial wages is positive.

With only these three added controls, the relationship between income and hedging is negative and associated with a large standard error. On average, individuals who have portfolios close to the average in their initial occupation (i.e. portfolios with limited hedging) experience higher earnings. From the adjacent column, these results change very little after adding the control STAY which accounts for occupation change. Those who never switch occupations tend to earn less (the estimated coefficient equals -0.050 ) but there is a fairly large amount of uncertainty around that value (the p-value is $18.6 \%$ ). The negative estimated coefficient implies negative returns to occupational tenure, which would appear to contradict some previous findings in the literature. ${ }^{15}$

Some occupational transitions are primarily lateral moves for people who want to

\footnotetext{
${ }^{13}$ The division of human capital into three types of skills is obviously not the only one possible. To assess the sensitivity of the empirical results to an alternative division, we considered four types, with humanities and fine arts representing two different categories. The results are very similar to those obtained with three types of skills and for that reason reported in an appendix.

${ }^{14}$ Initial earnings are denoted by $\log \left(Y_{1}\right)$ since the first year of a labor market history is individualspecific and does not correspond to a unique calendar year.

${ }^{15}$ See, for example, Kambourov and Manovskii (2009). However, Groes, Kircher, and Manovski (2009) note that not all occupational switches are created equal. Movements to occupations higher in the hierarchy (e.g. managerial occupations) should be associated with increases in earnings. Using Danish data they find that the best-performing and the worst-performing workers in an occupation are more likely to switch than those in the middle. Below we show that our data confirms that some occupational switches (e.g. those that end in managerial positions) are associated with increases in earnings.
} 
or are induced to do something else. Some job changes are natural progressions up a career ladder. To control for the more vertical (as opposed to horizontal) moves, the third column of results includes a dummy variable, CAREER, which equals one for occupational switches (only comparing the first and last period in an individual's labor market) that end in managerial positions either from sales, clerical, or other professional occupations and zero otherwise. Not surprisingly, the estimated coefficient of CAREER is positive and the estimate for STAY becomes small and insignificant.

The last column of Table 3 offers interesting evidence on portfolio hedging. This regression specification includes an interaction term between occupational switchers and the diversification measure, $\delta \times S T A Y$. The effects are intriguing. The coefficient on this interaction term is negative, significant and large $(-0.38)$ implying that individuals who do not switch occupations and who have portfolios close to those found in the first occupation have on average higher earnings growth. Moreover, since the coefficient on $\delta$ itself switches signs and turns positive (0.164), it appears that if an individual switches occupations (STAY $=0$ ), a flexible portfolio pays off. A portfolio further away from the average portfolio of the previous occupation is associated with a higher growth rate in earnings. Although the $p$-value is fairly large $(11.5 \%)$ hence the degree of uncertainty in this estimated coefficient is large, these results are informative given the sample size and the relatively higher number of "stayers." Note as well that the coefficient on STAY becomes positive (0.112) with a fairly small p-value of $1.8 \%$. On average higher earnings occur for those that remain in an occupation once we take into account their portfolio diversification. ${ }^{16}$

Finally, Table 4 reports results from a Probit model with STAY as the dependent variable. Recall that variable takes the value one if the individual never switches occupations and zero otherwise so these estimates relate to occupational mobility. In all four specifications of the controls, the relationship between hedging and the proba-

\footnotetext{
16 The pattern of these regressions is robust. It remains unchanged if we use unweighted credits or alternative measures of mismatch in the initial occupation. Likewise, the pattern remains the same if income growth is used as the dependent variable.
} 
bility of an occupational transition is negative. In other words, the further away an individual's portfolio is from the average portfolio of his first occupational choice, the more likely they are to switch to a different occupation. Women are on average more likely to switch but the relationship between the two variables is weak (the p-value is 0.76). Individuals with a larger number of credits are more likely to stay in their first occupational choice, as are individuals who start with relatively high initial earnings.

\section{The Portfolio Problem}

The results presented above suggest that specialization as well as risk diversification are important considerations in determining the acquisition of job market skills and the subsequent labor market experience. A more thorough empirical assessment requires a more fully specified economic framework. This section therefore presents a decisiontheoretic model in which individuals optimally choose a vector of skills, or human capital types, when future occupational fit is uncertain.

\subsection{Environment}

Suppose individuals with discount factor $\beta \in(0,1)$ live for an infinite number of discrete periods, $t=0,1,2, \ldots$. Individuals choose their human capital investments, i.e. their set of individually distinct skills, in the initial period $(t=0)$ to optimize expected discounted lifetime earnings. There are $K$ skills that can be employed in $J$ occupations. All occupations value all skills but to different degrees. Denote an individual portfolio of skills by $\boldsymbol{h}=\left\{h_{1}, \ldots, h_{K}\right\}$.

Individuals are well aware of their individually specific ability to accumulate or invest in the different skills that make up their skill portfolio. Before choosing $\boldsymbol{h}$, an individual draws a vector of abilities for each type of human capital, $\xi=\left(\xi_{1}, \ldots, \xi_{K}\right)$ from $F(\xi)$. The element $\xi_{k}$ represents an individual's capacity to accumulate skill of type $k$. The total cost (in utils) of investing in an individual's portfolio is given by 
$C(\boldsymbol{h}, \mathfrak{\xi}): \mathbb{R}^{2 K} \rightarrow \mathbb{R}$ which is increasing in the size of the human capital stock, decreasing in the level of each ability, convex and twice differentiable.

Individuals also know the payoff structure of each occupation. They are well aware of the technology that maps a human capital portfolio into earnings. They are, however, unsure about an idiosyncratic component of labor market payoffs. Before choosing $\boldsymbol{h}$, individuals receive a noisy signal of their fit in each occupation - they draw a vector $\boldsymbol{\theta}=\left(\theta_{1}, \ldots, \theta_{J}\right)$ from the distribution $G(\boldsymbol{\theta})$. Each element $\theta_{j}$ is an uncertain indication about an individual's future productivity in occupation $j \in\{1, \ldots, J\}$.

Once an individual has acquired the skill set $\boldsymbol{h}$, they enter the labor market in the next period $t=1$. At this point, workers are unable to update or modify their mix of skills. Individuals' only choice in the labor market is to decide in which occupation to work. They can work in only one occupation in a period. Although individuals have a general idea before they invest in their portfolio of skills of how well they are likely to fit into a given occupation, it is only after they complete training and after they work for a while in a particular job that their true fit in that profession becomes known. Actual experience in an occupation reveals an individual's true match quality or future productivity in that occupation. ${ }^{17}$

Acquired skills, productivity signals and labor market experience determine payoff flows. Assume that the first time individuals try an occupation, they start in a probationary phase during which they get paid according to their noisy signal. In particular, if an individual who has skills $\boldsymbol{h}$ along with signals $\boldsymbol{\theta}$ decides to work in occupation $j$ for the first time, the flow payoff or earnings equals $e^{\theta_{j}} f_{j}(\boldsymbol{h})$. The function $f_{j}: \mathbb{R}^{K} \rightarrow \mathbb{R}$ is a constant returns to scale technology that maps a given portfolio of skills into earnings. We allow this technology to differ by occupation, hence the subscript $j$.

An individual completes the probationary phase in occupation $j$ with probability $\pi$ at the end of each period. When this phase stops, the worker's productivity gets

\footnotetext{
${ }^{17}$ We use the term productivity or match-quality interchangeably. This term corresponds to the component of earnings in an occupation unaccounted for by the individual's portfolio of skills.
} 
updated by adding to the $\theta_{j}$ signal an independent random shock $\epsilon_{j}$ drawn from a distribution $\Gamma_{j}$. Should an individual decide to remain in that occupation after ending probation and learning their true productivity, earnings then begin to grow at a gross rate of $\gamma>1$, with $\beta \gamma<1$.

Information revelation is thus sequential. At each point in time, individuals decide whether to remain in their current occupation or to continue exploring new occupations. Exploration enlarges the information set as individuals learn about their matchquality. This setup is a classic multi-armed bandit problem in which the exploration of an arm (an occupation) comes at the expense of obtaining payoffs, that are perhaps larger, in alternative arms. ${ }^{18}$

\subsection{The Individual's Problem}

Let $V\left(\boldsymbol{\theta}, \boldsymbol{h}, \boldsymbol{\Phi}_{t}\right)$ denote the expected labor market payoff to an individual with skills $\boldsymbol{h}$, productivity signals $\boldsymbol{\theta}$, and labor market history $\boldsymbol{\Phi}_{t}$ at date $t$. An individual with known abilities vector $\xi$ therefore chooses a set of skills in period $t=0$ to solve ${ }^{19}$

$$
\max _{\boldsymbol{h}}-C(\boldsymbol{\xi}, \boldsymbol{h})+\beta V(\boldsymbol{\xi}, \boldsymbol{h}, \varnothing) .
$$

Given skills, signals and history, $V($.$) is the maximum discounted expected lifetime in-$ come that the individual can attain when the only action available is whether to switch occupations. In period $t=0$, the worker has not yet entered the market so that $\Phi_{0}$ is the empty set. In subsequent periods, labor market histories consist of occupations chosen in previous periods along with the realized draws of true productivity or fit in those occupations:

$$
\Phi_{t}=\left\{\left(j_{s}, \epsilon_{j_{s}}\right)\right\}_{s=1}^{t-1} .
$$

\footnotetext{
${ }^{18}$ Early economic applications of the classical multi-armed bandit model include Weitzman (1979) and Miller (1984). More recent examples include Papageorgiou (2009) and Papageorgiou (2011).

${ }^{19}$ For the sake of clarity, we do not subscript every function by an $i$. It should be understood that except occupation-specific technologies and the cost function, all other objects are specific to an individual.
} 
where the $\epsilon_{j_{s}}$ appropriately convey if and when the probationary phase in occupation $j$ finished.

Expected earnings in the labor market, $V$, can be written recursively given the appropriate choice of occupation:

$$
V\left(\boldsymbol{\theta}, \boldsymbol{h}, \boldsymbol{\Phi}_{t}\right)=\max _{j_{t} \in\{1, \ldots, J\}} w_{j_{t}}\left(\theta_{j_{t}}, \boldsymbol{h}, \boldsymbol{\Phi}_{t}\right)+\pi \beta \mathbb{E}_{\epsilon_{j_{t}}} V\left(\boldsymbol{\theta}, \boldsymbol{h}, \boldsymbol{\Phi}_{t+1}\right)+(1-\pi) \beta V\left(\boldsymbol{\theta}, \boldsymbol{h}, \boldsymbol{\Phi}_{t+1}\right),
$$

where $w_{j}\left(\theta_{j}, \boldsymbol{h}, \mathbf{\Phi}_{t}\right)$ is the immediate flow payoff in occupation $j$ given skills and history. The notation makes clear that recalling previous occupations is allowed. ${ }^{20}$ Let $\eta_{j}\left(\Phi_{t}\right)$ denote the number of periods an individual worked in occupation $j$ with knowledge of her true productivity. Recalling that after acquiring that knowledge, earnings grow with experience in an occupation and that the fit in an occupation does not vary over time after learning takes place, $\left(\epsilon_{j_{t}}=\epsilon_{j_{t^{\prime}}}\right.$ if $j_{t}=j_{t^{\prime}}$ and $\eta_{j}>0$ at $\left.t, t^{\prime}\right)$ the flow payoff in a period can be written as

$$
w_{j}\left(\theta_{j}, \boldsymbol{h}, \boldsymbol{\Phi}_{t}\right)=\left\{\begin{array}{cc}
e^{\theta_{j}} f_{j}(\boldsymbol{h}) & \text { if } \eta_{j}\left(\Phi_{t}\right)=0 \\
e^{\theta_{j}+\epsilon_{j}} f_{j}(\boldsymbol{h}) \gamma^{\eta_{j}\left(\Phi_{t}\right)} & \text { if } \eta_{j}\left(\Phi_{t}\right)>0 .
\end{array}\right.
$$

Repeated sampling of a given occupation provides no new information about alternative occupations. If probation has not ended, i.e. learning has not taken place, the employer and employee both know $\theta_{j}$ and $\boldsymbol{h}$, but neither knows $\epsilon_{j}$. As a result, individual pay reflects only the noisy signal and human capital. After the individual has completed probation and learned her true fit, the flow payments equal the true productivity - determined by the signal $\theta_{j}$ and updated with $\epsilon_{j}$ - which grows with occupation-specific tenure at rate $\gamma>1$. This update becomes part of the individual's information set whether or not they decide to remain in occupation $j$.

\footnotetext{
${ }^{20}$ The expression does not include an expectations operator if the probationary phase does not end. In this case, the notation emphasizes and makes clear whether learning occurs in the history $\Phi_{t+1}$.
} 


\subsection{Switching versus Staying}

The optimal portfolio choice involves computing the expected discounted value of earnings after entering the labor market, given by $V(\boldsymbol{\theta}, \boldsymbol{h}, \varnothing)$. Policies controlling occupational choice, $j_{t}$, determine the realization of potential outcomes over time and reflect a trade-off between exploring new occupations - therefore obtaining information about fit - and exploiting the current occupation where payoffs are known.

This exploration versus exploitation trade-off is characteristic of multi-armed bandit problems. Arms correspond to occupations with individuals sampling at most one arm per period. Gittins and Jones (1972) reduce the dimensionality of bandit problems by demonstrating that the solution to these problems takes the form of an index policy. They formulate the so-called Gittins index which assigns a value to each option that depends only potential outcomes in that option. The chosen occupational choice is the option with the highest index.

Whittle (1982) reformulates this approach in such a way that the index reflects a retirement value for each choice. Following Whittle's approach, the Gittins or retirement index for an occupation in which true productivity is known (the individual completed probation) is simply the lifetime value of income in that occupation:

$$
\begin{aligned}
M_{j}\left(\theta_{j}, \boldsymbol{h}, \boldsymbol{\Phi}_{t}\right)= & \gamma^{\eta_{j}\left(\Phi_{t}\right)} w_{j}\left(\theta_{j}, \boldsymbol{h}, \boldsymbol{\Phi}_{t}\right) /(1-\beta \gamma) \\
& =e^{\theta_{j}+\varepsilon_{j}} f_{j}(\boldsymbol{h}) \gamma^{\eta_{j}\left(\Phi_{t}\right)} /(1-\beta \gamma) \quad \text { for } \eta_{j}\left(\mathbf{\Phi}_{t}\right)>1
\end{aligned}
$$

On the other hand, if productivity in occupation $j$ is unknown because it has either not been tried or because the true productivity has not yet been revealed, the index must account for the unresolved uncertainty. In general, the index is given by

$$
M_{j}=\sup _{\tau}(1-\beta)\left\{\mathbb{E}\left[\sum_{t=0}^{\tau-1} \beta^{t} w_{j}\left(\theta_{j}, \boldsymbol{h}, \boldsymbol{\Phi}_{t}\right)+\frac{\beta^{\tau}}{1-\beta} M_{j}\right]\right\}
$$

where $\tau$ is a stopping rule that is contingent on the sequence of events or draws in 
occupation $j$.

Recall that with probability $\pi$, all information about true productivity in occupation $j$ is revealed in each period of probationary employment in $j$. Once the true productivity is revealed, there is no further learning and workers will choose to either move to another occupation or remain forever in $j$. Hence once productivity is revealed, $\tau \in\{1, \infty\}$. On the other hand, if learning does not occur, workers face the same problem as the previous period. Given that wage growth through $\gamma$ does not occur until productivity is found out, the decision is stationary. The Gittins index therefore reduces to

$$
\begin{aligned}
M_{j}= & (1-\beta)\left[(1-\pi)\left\{e^{\theta_{j}} f_{j}(\boldsymbol{h})+M_{j}\right\}\right. \\
& \left.+\pi \mathbb{E}_{\epsilon_{j}} \max \left\{e^{\theta_{j}} f_{j}(\boldsymbol{h})+\frac{\beta}{1-\beta} M_{j}, e^{\theta_{j}} f_{j}(\boldsymbol{h})+\frac{\beta \gamma}{1-\beta \gamma} e^{\theta_{j}+\epsilon_{j}} f_{j}(\boldsymbol{h})\right\}\right]
\end{aligned}
$$

Given this simple choice, a simple reservation value for revealed productivity determines continuation in occupation $j$. Let $\epsilon_{j}^{R}$ denote the critical value of $\epsilon_{j}$ that equates the two options. With an $\epsilon_{j}^{R}$ draw from the distribution $\Gamma_{j}$, the individual is indifferent between retiring from $j$ and remaining permanently:

$$
(1-\beta) e^{\theta_{j}} f_{j}(\boldsymbol{h})+\beta M_{j}=(1-\beta) e^{\theta_{j}} f_{j}(\boldsymbol{h})+\frac{\beta \gamma(1-\beta)}{1-\beta \gamma} e^{\theta_{j}+\epsilon_{j}^{R}} f_{j}(\boldsymbol{h})
$$

which yields

$$
\epsilon_{j}^{R}=\ln \left(\frac{(1-\beta \gamma) M_{j}}{(1-\beta) \gamma f_{j}(\boldsymbol{h})}\right)-\theta_{j}
$$

This reservation cutoff does not depend on the probability of learning except through the Gittins index $M_{j}$. Plugging $\epsilon_{j}^{R}$ into (1) and manipulating gives

$$
M_{j}\left(\theta_{j}, \boldsymbol{h}, \boldsymbol{\Phi}_{t}\right)=\frac{(1-\beta) e^{\theta_{j}} f_{j}(\boldsymbol{h})\left(1-\beta \gamma+\beta \gamma \pi \int_{\epsilon_{j}^{R}}^{\infty} e^{\epsilon} d \Gamma_{j}(\epsilon)\right)}{(1-\beta \gamma)\left[1-\beta+\beta \pi\left(1-\Gamma\left(\epsilon_{j}^{R}\right)\right)\right]} \text { for } \eta_{j}\left(\boldsymbol{\Phi}_{t}\right)=0
$$

which can be solved, at least numerically, given a parameterization $\Gamma_{j}$ and $f_{j}$. 
Proposition 1: Suppose updates to the productivity signals are bounded above and below such that $\epsilon_{j} \in(\underline{\epsilon}, \bar{\epsilon}) \forall j \in\{1, \ldots, J\}$. For any set of signals, skills and histories $\left(\boldsymbol{\theta}, \boldsymbol{h}, \boldsymbol{\Phi}_{t}\right)$, occupational choice $j_{t}$ solves

$$
j_{t}=\arg \max _{j}\left\{M_{1}\left(\boldsymbol{\theta}, \boldsymbol{h}, \boldsymbol{\Phi}_{t}\right), \ldots, M_{J}\left(\boldsymbol{\theta}, \boldsymbol{h}, \boldsymbol{\Phi}_{t}\right)\right\},
$$

The occupational choice problem is a comparison of reservation values for each occupation. The payoffs are the values that make the worker indifferent between continuing with an occupation or receiving the reservation payoff.

\section{Model Estimation}

To quantitatively assess the model, assume there are $K=3$ human capital or skill types, labeled Humanities (H), Quantitative (Q), and Social Science (SS). Assume the number of occupations equals $J=12$. These skills and occupations correspond to the HS\&B variables described in Section $2 .^{21}$

To keep the model parsimonious, we assume that occupational signals $\theta_{j}$ and the productivity updates $\epsilon_{j}$ are all independent and distributed normally

$$
\begin{aligned}
& \theta_{j} \sim N\left(0, \sigma_{\theta}\right) \quad j=1, \ldots, 12 \\
& \epsilon_{j} \sim N\left(0, \sigma_{\epsilon_{j}}\right) \quad j=1, \ldots, 12 .
\end{aligned}
$$

Note that we assume that the occupational signals $\theta_{j}$ all have the same variance as well as mean.

\footnotetext{
${ }^{21}$ To lower the number of parameters, we eliminate individuals who are listed as Owner, due to the low number of respondents with Owner as their first occupation.
} 
The abilities vector $\xi$ is distributed as,

$$
\xi \sim N\left(\mathbf{0}, \Sigma_{\xi}\right)
$$

The off-diagonal elements of $\Sigma_{\xi}$ are all assumed to have the same covariance $\rho_{\tilde{\xi}}$, a parameter driving the correlation in overall ability. Let $\sigma_{H}^{2}, \sigma_{Q^{\prime}}^{2}$ and $\sigma_{S S}^{2}$ denote the three diagonal elements of this matrix.

It is likely that for the individuals in our dataset the ability to acquire particular skills, $\boldsymbol{\xi}$, will be correlated with the signals of occupational aptitude, $\boldsymbol{\theta}$. Individuals who have a higher verbal ability than quantitative ability in school might perceive relatively more encouraging signals about their productivity in the legal profession. However, the relationship between schooling talent and occupational fit is not readily captured in a small number of parameters. There are three human capital types that get used in different ways in twelve occupations. Imposing a simplifying relationship could arbitrarily constrict the data in unintended ways and unintentionally sway the estimation. To avoid prejudicing the results in this way and to keep the number of parameters manageable, we maintain throughout that the two vectors are independent.

This independence, however, does not imply zero correlation between abilities and the propensity of agents to work in particular occupations. For example, if writing well is a skill demanded from lawyers, students with high writing ability will tend to be lawyers, even though the correlation between writing ability and the noisy signal of the student's future productivity as a lawyer is zero. The reason is simply because high ability implies a relatively low cost of acquiring the skill. Choosing optimally, the student will put the skill to work in a profession where the skill is used intensively.

The cost function for acquiring skills is assumed to be additive and quadratic

$$
C(\xi, h)=\sum_{k \in\{H, Q, S S\}} e^{\tilde{\xi} k} h_{k}^{2}
$$


while the production technology is Cobb-Douglas ${ }^{22}$

$$
f_{j}(\boldsymbol{h})=\prod_{k \in\{H, Q, S S\}} h_{k}^{\alpha_{j, k}}, \sum_{k \in\{H, Q, S S\}} \alpha_{j, k}=1 .
$$

Set $\beta \gamma$ equal to 0.91 and fix $\gamma$ to be consistent with average earnings growth observed in the data, around 7.5\% per year, resulting in values for $\gamma$ and $\beta$ equal to 1.071 and 0.85 , respectively. As a result of these assumptions and normalizations, the vector of parameters ${ }^{23}$ for estimation is given by

$$
\Lambda=\left\{\left\{\alpha_{j, H}, \alpha_{j, Q}\right\}_{j=1}^{12},\left\{\sigma_{\epsilon_{j}}\right\}_{j=1}^{12},\left\{\sigma_{\xi_{k}}\right\}_{k \in\{H, Q, S S\}}, \rho_{\xi}, \pi, \sigma_{\theta}\right\}
$$

\subsection{Estimation Methodology}

We use a Simulated Method of Moments (SMM) approach to estimate the 42 elements of the structural parameter vector. Let $\hat{\Lambda}$ denote the parameter estimates and $\hat{\Omega}$ the associated estimated covariance matrix. The first step is to choose a vector of auxiliary moments from the HS\&B dataset, denoted by $Y$, which describe statistics about occupational transitions, skills portfolios across occupations, the dispersion of (log) earnings, and correlations across skills. Given a value of the structural vector $\Lambda$, the model can be solved and simulated. This simulation yields a model-analog for the vector $\mathrm{Y}$, denoted by $\hat{Y}$. The estimate $\hat{\Lambda}$ is then the value of $\Lambda$ that solves the following

\footnotetext{
${ }^{22}$ There is little information to guide our choice for a cost function. In results not reported here we assess the robustness of deviating from a quadratic specification by assuming an exponential function. Similarly, the available data do not allow estimation of the elasticity of substitution among different human capital types within an occupation. Although we impose Cobb-Douglas payoffs, we also estimated results assuming for CES production. In both instances, the results are robust to these alternative specifications.

${ }^{23} \mathrm{By}$ the constant-returns assumption, the weight of the third skill type is given once we know the other two.
} 
criterion: 24

$$
\hat{\Lambda}=\underset{\Lambda}{\operatorname{argmin}}(\mathrm{Y}-\hat{\mathrm{Y}})^{\prime}(\mathrm{Y}-\hat{\mathrm{Y}})^{\prime}
$$

Standard numerical routines solve this minimization problem. To provide a sense of the amount of uncertainty surrounding our estimates, numerical standard errors are computed following Gourinchas and Parker (2002):

$$
\hat{\Omega}=\left(\hat{H}_{\Lambda}^{\prime} \hat{H}_{\Lambda}\right)^{-1} \hat{H}_{\Lambda}^{\prime} \Omega_{\hat{Y}} \hat{H}_{\Lambda}^{\prime}\left(\hat{H}_{\Lambda}^{\prime} \hat{H}_{\Lambda}\right)^{-1}
$$

where $\hat{H}_{\Lambda}^{\prime}$ is the Jacobian matrix of the vector-valued function $H(\Lambda)=\hat{Y}-Y_{\Lambda}$ evaluated at $\Lambda=\hat{\Lambda}$. In other words, the $i j^{\text {th }}$ element of $\hat{H}_{\Lambda}$ is $\hat{h_{i j}}=\partial\left(\mathrm{Y}_{j}-\hat{\mathrm{Y}}_{j}\right) / \partial \Lambda_{i}$. $\Omega_{\hat{\mathrm{Y}}}$ is the variance matrix of the set of moments in $\hat{Y}$.

Table 5 displays the statistics found for Y. The columns labeled $\omega_{H}$ and $\omega_{Q}$ report average shares of a skill type - humanities and quantitative - in an individual's portfolio, averaged across individuals in a given occupational group. The $\omega_{H}$ column corresponds approximately to the "Share of Humanities" moment reported in Table 1. The column $\omega_{Q}$ corresponds to "Share of Quantitative " in Table 1. ${ }^{25}$ The last column of Table 5 reports the share of individuals that began their labor market career in a given occupation but switched in the second year. These shares range from a high of about one half in Service to a low of $5.1 \%$ for Engineers.

The two vectors of average shares for the two human capital types, $\omega_{H}$ and $\omega_{Q}$, identify the 24 technological parameters $\alpha_{j, H}$ and $\alpha_{j, Q}, j=1, \ldots 12$. The fractions of individuals who leave an occupation after one year identify the 12 variances, $\sigma_{\epsilon_{j}}^{2}$, associated with each occupation $j=1, \ldots, 12$. Occupations in which updates to the productivity signals have a large variability will experience a larger fraction of transitions. The

\footnotetext{
${ }^{24}$ In general, the criterion contains a weighing matrix $W$ :
}

$$
\hat{\Lambda}=\underset{\Lambda}{\operatorname{argmin}}(\mathrm{Y}-\hat{\mathrm{Y}})^{\prime} \mathrm{W}(\mathrm{Y}-\hat{\mathrm{Y}})^{\prime}
$$

All results shown below assume all moments carry equal weight, hence $W=I$.

${ }^{25}$ For some occupations the values are not exactly the same across the two tables. The difference is a consequence of having eliminated individuals who reported having ever being occupied as Owners. 
larger variability is itself a consequence of being more likely that the Gittins index for those volatile occupations, after they are explored, falls below the second-best Gittins index.

Eight aggregate moments complete the set of moments that comprise the parameter vector $Y$. The standard deviation of (log) earnings across all individuals in the first year of labor market experience identifies $\sigma_{\theta}$, which is the main driver of income differences (in levels) in the first year. Measures of the dispersion across individuals' portfolio shares of the three different skills helps identify the three diagonal elements of $\Sigma_{\xi}$. The moment labeled percentage of "Stay-Switch Events" is defined as the fraction of workers whose occupational choice is the same in periods 1 and 2 but different in period 3. That fraction in the data is $8.8 \%$ (of all workers, not of all switchers). Finally, we also target the three cross-correlations in credits across skills.

In principle one could include the model-analog coefficients shown in Table 3 as additional moments in the estimation and formally test the over-identifying restrictions. We have decided not to do so as they involve the variable $\delta$. While $\delta$ provides an intuitive measure of distance or the degree of hedging against adverse shocks, it is imperfect and somewhat arbitrary. It is neither a conceptually clean benchmark nor an object that arises naturally in the model. As a consequence we leave the regression coefficients in Table 3 outside of the estimation procedure. In the next section, however, we examine the model-analog to the reduced-form coefficients in Tables 3 and 4 using our estimated structural parameters.

Given a vector of structural parameters $\Lambda$, we simulate labor market histories for a large number of individuals by taking a $(\boldsymbol{\xi}, \boldsymbol{\theta})$ draw from the abilities and productivity signals distributions. Given these draws and a portfolio of skills, we solve for the expected earnings by finding the optimal sequence of occupational switches for each possible update of the productivity signals. The optimal portfolio is the one which maximizes the difference between the maximum expected earnings in the labor market and the cost of purchasing it. This procedure yields the optimal portfolio of one 
individual as well as a randomly selected simulated labor market history. Repeating those steps for a large number of individuals provides the model-analog to the moments in the vector $\mathrm{Y}(\Lambda)$. The appendix provides further details of this estimation routine.

\section{Results}

\subsection{Parameter Values}

Table 6 reports the elements of $\hat{\Lambda}$, along with their estimated numerical standard errors. These parameters tend to be tightly estimated. Dispersion in the productivity update for Other Professionals $\left(\hat{\sigma}_{\epsilon_{\text {Prof-Other }}}\right)$ is one exception. The estimated standard error is nearly three times the parameter estimate. A second exception is the estimated humanities component in production function for Computer Technicians, $\hat{\alpha}_{\text {Tech.-Comp,H }}$. The associated standard error is one and a half larger than the parameter estimate. Otherwise, the standard errors of the other parameters are generally small relative to the estimates.

Notice as well that the estimated Cobb-Douglas shares roughly follow the pattern found in the average portfolio weights across occupations. Compare $\hat{\alpha}_{H}$ and $\hat{\alpha}_{Q}$ with $\omega_{H}$ and $\omega_{Q}$ in Table 5. Production displays substantial variation in the use of skills across occupations.

Uncertainty in the post-probation fit, $\hat{\sigma}_{\epsilon}$ (which is related to the probability of exiting an occupation) also varies considerably across occupations. Consider one of the riskiest occupations, Professionals of the Arts. It not only has a relatively high estimated standard deviation of shocks, $\hat{\sigma}_{\epsilon_{j}}=.387$, but the technology is also heavily tilted towards humanities with $\hat{\alpha}_{\text {Prof.Arts, } H}=0.687$. However, individuals in this profession have portfolios with a humanities weight of only $52 \%$. A high weight in humanities is risky by itself as humanities is not very portable across occupations. The profession with the second highest $\hat{\alpha}_{j, H}$ is Service, with a much smaller value of $31 \%$. Moreover, 
the high volatility of shocks in this profession amplifies this risk leading to a high switching probability. High turnover makes diversification all the more attractive.

Although this pattern is not so extreme in other occupations, the average portfolios across individuals tends to be more balanced than the Cobb-Douglas technology parameters, as one might anticipate from hedging behavior. Professional of the Arts, Service, and Skilled Operatives appear to be high risk as measured by $\hat{\sigma}_{\epsilon_{j}}$ while Managers, Medical and Other Professionals are safer. Note as well that the uncertainty in the occupational fit is highest in those professions that emphasize humanities skills, i.e. those with highest $\hat{\alpha}_{j, H}$.'s

Dispersion in abilities differs across types of human capital. The ability to acquire quantitative skills is highly concentrated (the variance is 0.217 ) relative to the ability to study humanities (0.933) and especially social science (1.81). Workers appear to learn about their true productivities relatively fast: the estimated value of $\pi$ is 0.86 . Finally, the estimate of $\hat{\rho}_{\xi}$ is -0.26 . At first, this estimate might appear peculiar. The sample, however, focuses on college students. As shown in Table 2 the distribution of credits is concentrated. As a result, more credits in a given type of human capital will generally imply fewer credits in other types (consistent with the three correlations shown in Table 5). The estimated covariance reflects this feature of the data.

\subsection{Goodness of Fit}

The estimates in Table 6 map out an explicit as well as involved trade-off between specialization and hedging. Before considering this trade-off further, we now examine how well the estimated model replicates outcomes observed in the labor market that were not targeted as part of the estimation procedure. Since occupational switching and dispersion in initial earnings were targets of the estimation, the focus turns to earnings in 1991 to assess the performance of the model. In simulations of the model, income levels depend upon arbitrary normalizations of parameters, hence comparing income distributions is not interesting. We therefore compare the distributions of in- 
come growth in the data and the model.

Table 7 provides statistics from the distribution of (annual) income growth, both for the HS\&B sample of students and for the estimated model. Dispersion in the observed data exceeds dispersion in the model. The standard deviation of the distribution of income growth in the simulated distribution is roughly $60 \%$ of that in the data. This difference is not surprising. In reality individual earnings vary after workers settle in an occupation. The construction of the model rules out such shocks and changes to earnings that occur after exploration of occupations in the labor market ends.

The model rules out other possibilities. Students do not update their beliefs on their occupational calling while at university. They also cannot update their skill set when they switch professions. Students, of course, change majors and workers can improve the alignment of their skills after they settle on an occupation. On the other hand, such career learning while studying may well occur early on and thus not drastically alter the desired make-up of acquired of skills. Many changes in majors occur when students are just beginning their studies. Intended majors can change even before first year enrollment. Likewise, workers who do not switch also acquire on-the-job skills. Acquiring fundamental skills when young is often less costly, more enduring and easier to build upon. The impact of poorly aligned skills may be long lasting. There are many possibilities yet little direct evidence guiding these abstractions.

Despite these limitations, the model generates an earnings growth distribution with a substantial amount of inequality that shares important characteristics with earnings growth responses found in the HS\&B survey. The minimum growth rate observed in both distributions is similar $(-0.219$ in the data and -0.194 in the model). Because the model generates a modest right tail of the distribution of earnings growth - some individuals in the data report high positive growth rates compared to the highest values generated by the model, ${ }^{26}$ the simulated skewness is only $70 \%$ of the empirical counterpart. On the other hand, the model generates a substantial mass of negative

\footnotetext{
${ }^{26}$ One respondent in the data reports an average annual growth rate in earnings of $63 \%$.
} 
earnings growth rates (these are associated with occupational switchers), so that the simulated kurtosis is in the ballpark to that found in the data, 5.4 versus 6.2.

To further explore the relationships among income, diversification in human capital portfolios and individual occupational transitions, Table 8 replicates the regressions from Table 3 on model-simulated data. Obviously, not all of the control variables employed in the analysis with actual data in Section 2 are available with our modelgenerated output. Gender is absent in the simulated model and occupations in the model are exclusively horizontal. There are no vertical career transitions. Hence, SEX and CAREER do not appear in the simulated regressions. The remaining variables $\log \left(Y_{1}\right), \log (C R E D), \delta$, and $S T A Y$ - are constructed the same way as in the actual data. To ease the comparison between model and data, the last two columns report the same coefficients found when fitting the regression to actual data. The first two columns display results with model-generated data.

In Table 8, the coefficient estimates from simulated data compare favorably to those estimated from the observed data. Although the simulated data abstract from a number of factors (some are mentioned above while others involve familiar variables related to wages determination), the estimates are all roughly in line with the HS\&B empirical estimates. The coefficient on initial earnings (around $0.75-0.85$ ) is somewhat higher than in the data. The model generates this large and positive coefficient because those with high initial earnings have strong signals and hence portfolios targeted to the first occupation. They are less likely to switch, accruing growth for a larger number of periods resulting in higher earnings. When we condition on switching, the positive coefficient on STAY ( 0.28 which is higher than the empirical counterpart of 0.11 ) reflects simple selection. Those who stay in the job receive good $\epsilon$ draws and earn more relative to similar workers who try other occupations.

Now consider the relationship between hedging, earnings, and occupational exploration. Note first that the coefficient on $\delta$ displays the same pattern as found in HS\&B data. Without controls for occupation switches, the coefficient estimates in the 
observed and simulated data are negative with large standard errors. Controlling for mobility switches the sign of this coefficient, increases the magnitude and lowers the standard error. For an individual who switches occupations $(S T A Y=0)$, the coefficient of $\delta$ on $(\log )$ earnings is about 0.08 , somewhat lower than that found in the data (0.16). The coefficient on the interaction term $\delta \times S T A Y$ is lower $(-0.135)$ in absolute value than its empirical counterpart (-0.379) but implies that, everything else constant, portfolio distance decreases stayers' earnings.

Replicating Table 4, Table 9 reports Probit estimates from the model generated data in which the probability of switching occupations is a function of the distance measure and other observables. The first two columns of the table display coefficients when fitted to the occupational transitions found in our model-simulated data. The last two columns of Table 9 display the relevant estimates from the first and last columns of Table 4 . The simple model again matches up fairly well with the magnitudes of the coefficients on initial earnings (roughly 0.5) and overstates somewhat the association between the probability of switching and our measure of distance in the portfolios.

\subsection{Counterfactual Earnings Distributions}

The $Y$ estimates in Table 6 shape the trade-offs an individual confronts when choosing a portfolio of skills to acquire before entering the labor market. Idiosyncratic circumstances embodied in the $\xi$ and $\boldsymbol{\theta}$ draws pin down these trade-offs precisely for each individual. When deciding what and how much to study, each agent weighs up and balances a number of personalized uncertain options.

To condense and to abstract from the individual-specific components of occupational uncertainty, we present a basic thought experiment. We quantify the impact of restricting the portfolio choice on the distribution of earnings in the estimated model. Agents cannot hedge as they would like. The experiment attempts to capture a feature characteristic of European higher educations systems: their relative inflexibility when diversifying across areas of study. A student wishing to be a biologist is given a cur- 
riculum from which there is little freedom to deviate. The baseline model resembles an American system in which students have a relatively large degree of freedom to diversify across areas of study.

In the experiment (labeled "Optimal Specialization"), agents specialize by choosing their optimal portfolios as if they were to remain in that occupation forever. Let

$$
j^{\prime}=\arg \max _{j \in\{1, \ldots, J\}}\left\{\max _{h}-C(\boldsymbol{\xi}, \boldsymbol{h})+\beta e^{\theta_{j}} f_{j}(\boldsymbol{h}) /(1-\beta \gamma)\right\},
$$

Let the optimal portfolio associated with this optimal occupational choice be $\boldsymbol{h}^{\prime}$ We give $\boldsymbol{h}^{\prime}$ to individuals in the stochastic world, and construct earnings distributions.

The results of this experiment are Table 10. The first three columns present moments from the earnings distributions (growth and levels) from the simulated data when portfolio choice is unrestricted, distinguishing between individuals who switch occupations and those who do not. The first column reports $\mathbb{E}(\Delta Y)$, the cross-sectional average of earnings growth. The first number for "All" corresponds to the number reported in Table 7, 7.15\%. The second and third row report the same moment for "Switchers", 2.79\%, and for "Non-Switchers", 8.35\%. The second column reports the standard deviation of the logarithm of earnings in the $5^{\text {th }}$ period.

The model delivers an earnings distribution for "Non-Switchers" with more dispersion than that of the "Switchers". This is a common feature of the simulations: switchers experience lower growth in earnings and their distribution is relatively less disperse. On the other hand, earnings of those who remain in their initial occupation grow faster on average and their earnings distribution is more disperse. The standard deviation of earnings for all individuals is 0.47 ; for non-switchers is 0.40 and for switchers 0.45 .

Non-switchers enjoy higher earnings growth for two reasons. The first channel is the same self-selection mechanism discussed previously that makes switching optimal only in the event of a relatively low productivity shock. The second channel is the 
earnings growth of $\gamma$ that accrues for a longer time period if individuals do not switch. Switchers, on the other hand, enjoy lower earnings and earnings growth because they enjoy the geometric growth rate for a shorter period of time. In addition, occupational switches are often associated with a drop in earnings, more so in cases where the portfolio is tailored to the departing occupation. Finally, the table also reports the fraction of people who switch occupations; $22.50 \%$ with our estimated parameters.

The last three columns of Table 10 reports the moments of the experiment relative to the baseline case. When individuals are endowed with portfolios chosen under the restriction that they must specialize the fraction of switchers falls. This reduction is expected. Having a portfolio of skills precisely tailored to a particular occupation reduces the attraction of trying a new one. Switchers experience large drops in average growth rates. Average income growth of non-switchers also falls albeit much less than the switchers, as now more individuals who experience low shocks are inclined to remain in the first occupation. Taken together, average incomes also fall.

Table 11 reports results for the same experiment when we relax the assumption of unit-elasticity of substitution among human capital types. In the baseline case we impose a unit-elasticity (i.e. Cobb-Douglas) and here assume that payoffs take the form of a constant elasticity of substitution (CES) function. All other parameters are fixed at their estimated values. The table reports percentage changes relative to values obtained with the CES function when portfolio choice is unrestricted. The table shows that the quantitative implications of the experiment are amplified by the lower elasticity of substitution. Inequality found in the cross-sectional variability of earnings falls with forced specialization. Inequality falls for switchers because the threat of a larger income drop makes it optimal to "settle early" in an occupation. As a result, the average number of switches falls, lowering dispersion of earnings. Cross-sectional inequality among non-switchers also falls.

The mechanism generating this result is subtle. It is clear that with specialized portfolios occupational switches are more costly. The higher cost prevents individuals 
from trying high-risk occupations hoping to get a large productivity draw. With the unrestricted portfolio that option is relatively more attractive to workers because their fallback option is not as dismal as with the specialized portfolio. As a consequence the upper tail in the earnings growth distribution is absent in the counterfactual relative to the baseline. It is this upper tail in growth and hence in earnings that is responsible for the higher inequality among non-switchers in the baseline case. Consistent with the results displayed on the table, this effect is stronger, the lower the elasticity of substitution among human capital types.

\section{Concluding Remarks}

This paper assesses the way in which the composition of workers' skills interact with labor market uncertainty to determine the evolution of earnings. Human capital consists of a portfolio of imperfectly substitutable skills acquired through formal education. Different potential occupations value these skills differently and uncertainty about one's fit in any particular occupation introduces uncertainty in the investment decision. A trade-off arises between acquiring specialized skills targeted for a particular occupation and acquiring a package of skills that diversifies the risk across occupations.

Individual-level data on the amount of college credits across different subjects and labor market dynamics in early careers reveals that income is higher for the more specialized individuals who do not switch occupations whereas income is higher for more diversified individuals who switch occupations.

To further evaluate the tension between specialization and diversification, we construct and estimate a portfolio choice problem that features an interaction between skills, abilities, and uncertain labor market outcomes. The model replicates the basic patterns observed in the individual data and generates a sizable amount of inequality. Counterfactual earnings distributions found by endowing individuals with portfolios 
chosen under certainty about occupational fit illustrate that the underlying stochastic structure generates large effects both on the income growth distribution and the variance of earnings. 


\section{References}

Altonji, J. G. (1993): “The Demand for and Return to Education When Education Outcomes Are Uncertain," Journal of Labor Economics, 11(1), 48-83.

Antonovics, K., and L. Golan (2012): "Experimentation and Job Choice," Journal of Labor Economics, 30(2), 333 - 366.

Arcidiacono, P. (2004): "Ability sorting and the returns to college major," Journal of Econometrics, 121(1-2), 343-375.

Becker, G. S. (1994): Human Capital: A Theoretical and Empirical Analysis with Special Reference to Education (3rd Edition), NBER Books. National Bureau of Economic Research, Inc.

Ben-Porath, Y. (1967): “The Production of Human Capital and the Life Cycle of Earnings," Journal of Political Economy, 75(4 Pt. 1.), 352-65.

Gathmann, C., and U. Schönberg (2010): "How General Is Human Capital? A TaskBased Approach," Journal of Labor Economics, 28(1), 1-49.

Gervais, M., I. Livshits, and C. Meh (2008): “Uncertainty and the specificity of human capital," Journal of Economic Theory, 143(1), 469-498.

Gittins, J., and D. Jones (1972): A Dynamic Allocation Index for the Sequential Design of Experiments. University of Cambridge, Department of Engineering.

Gourinchas, P.-O., and J. A. Parker (2002): “Consumption Over the Life Cycle," Econometrica, 70(1), 47-89.

Groes, F. N., P. Kircher, and I. Manovski (2009): “The U-Shapes of Occupational Mobility," 2009 Meeting Papers 26, Society for Economic Dynamics. 
Heckman, J. J., and G. Sedlacek (1985): “Heterogeneity, Aggregation, and Market Wage Functions: An Empirical Model of Self-selection in the Labor Market," Journal of Political Economy, 93(6), 1077-1125.

Heckman, J. J., and G. L. Sedlacek (1990): "Self-selection and the Distribution of Hourly Wages," Journal of Labor Economics, 8(1), S329-63.

Huggett, M., G. Ventura, and A. Yaron (2011): "Sources of Lifetime Inequality," American Economic Review, 101(7), 2923-54.

James, J. (2011): “Ability matching and occupational choice," Working Paper 1125, Federal Reserve Bank of Cleveland.

Jovanovic, B. (1979): “Job Matching and the Theory of Turnover," Journal of Political Economy, 87(5), 972-90.

Kambourov, G., and I. Manovskii (2009): “Occupational Mobility and Wage Inequality," Review of Economic Studies, 76(2), 731-759.

Keane, M. P., and K. I. Wolpin (1997): “The Career Decisions of Young Men," Journal of Political Economy, 105(3), 473-522.

Kinsler, J., and R. Pavan (2012): “The Specifity of General Human Capital: Evidence from College Major Choice," Discussion paper, The University of Rochester.

Lazear, E. P. (2009): “Firm-Specific Human Capital: A Skill-Weights Approach,” Journal of Political Economy, 117(5), 914-940.

Levhari, D., and Y. Weiss (1974): “The Effect of Risk on the Investment in Human Capital," American Economic Review, 64(6), 950-63.

Malamud, O. (2010): “Breadth versus Depth: The Timing of Specialization in Higher Education," LABOUR, 24(4), 359-390. 
Miller, R. A. (1984): "Job Matching and Occupational Choice," Journal of Political Economy, 92(6), 1086.

Neal, D. (1999): “The Complexity of Job Mobility among Young Men," Journal of Labor Economics, 17(2), 237-261.

Papageorgiou, T. (2009): “Learning Your Comparative Advantages," 2009 Meeting Papers 1150, Society for Economic Dynamics.

(2011): “Worker Sorting and Agglomeration Economies," 2011 Meeting Papers 660, Society for Economic Dynamics.

Robst, J. (2007): "Education and job match: The relatedness of college major and work," Economics of Education Review, 26(4), 397-407.

Roy, A. (1951): "Some Thoughts on the Distribution of Earnings," Oxford Economic Papers, 3(2), 135-146.

Sanders, C. (2011): "Skill Uncertainty, Skill Accumulation, and Occupational Choice," Discussion paper, Washington University at St. Louis.

Sanders, C., and C. Taber (2012): “Life-Cycle Wage Growth and Heterogeneous Human Capital," Annual Review of Economics, 4(1), 399-425.

Schoellman, T. K. (2010): “The Occupations and Human Capital of U.S. Immigrants," Journal of Human Capital, 4(1), 1-34.

Smith, A. (1776): An Inquiry into the Nature and Causes of the Wealth of Nations, no. smith1776 in History of Economic Thought Books. McMaster University Archive for the History of Economic Thought.

Stigler, G. J. (1962): “Information and the Labor Market," Journal of Political Economy, 70(5), 94-105. 
Sullivan, P. (2010): “A Dynamic Analysis Of Educational Attainment, Occupational Choices, And Job Search," International Economic Review, 51(1), 289-317.

Topel, R. H., and M. P. Ward (1992): “Job Mobility and the Careers of Young Men," The Quarterly Journal of Economics, 107(2), 439-79.

Wasmer, E. (2006): “General versus Specific Skills in Labor Markets with Search Frictions and Firing Costs," American Economic Review, 96(3), 811-831.

Weitzman, M. L. (1979): “Optimal Search for the Best Alternative,” Econometrica, 47(3), $641-54$.

Whittle, P. (1982): Optimization Over Time, Dynamic Programming and Stochastic Control, Wiley series in probability and mathematical statistics . Applied probability and statistics. John Wiley \& Sons.

Willis, R. J. (1987): “Wage determinants: A survey and reinterpretation of human capital earnings functions," in Handbook of Labor Economics, ed. by O. Ashenfelter, and R. Layard, vol. 1 of Handbook of Labor Economics, chap. 10, pp. 525-602. Elsevier.

Yamaguchi, S. (2012): "Tasks and Heterogeneous Human Capital," Journal of Labor Economics, 30(1), $1-53$. 
Table 1: Empirical Human Capital Portfolios By Occupation (1991)

\begin{tabular}{lccc}
\hline Occupation & Share Hum. & Share Quant. & Share Soc. Sci. \\
\hline Clerical & 0.263 & 0.268 & 0.469 \\
& $(0.195)$ & $(0.216)$ & $(0.196)$ \\
Manager & 0.221 & 0.290 & 0.489 \\
& $(0.153)$ & $(0.223)$ & $(0.203)$ \\
Skilled Op. & 0.181 & 0.497 & 0.322 \\
& $(0.094)$ & $(0.284)$ & $(0.235)$ \\
Prof. Arts & 0.492 & 0.132 & 0.376 \\
& $(0.215)$ & $(0.088)$ & $(0.181)$ \\
Prof.- Medical & 0.227 & 0.427 & 0.347 \\
& $(0.125)$ & $(0.223)$ & $(0.201)$ \\
Prof. - Eng. & 0.098 & 0.760 & 0.142 \\
& $(0.076)$ & $(0.152)$ & $(0.111)$ \\
Prof. - Other & 0.231 & 0.281 & 0.488 \\
& $(0.165)$ & $(0.186)$ & $(0.209)$ \\
Owner & 0.175 & 0.259 & 0.565 \\
Sales & $(0.165)$ & $(0.206)$ & $(0.186)$ \\
& 0.244 & 0.239 & 0.517 \\
School Teacher & $(0.140)$ & $(0.151)$ & $(0.158)$ \\
& 0.330 & 0.285 & 0.385 \\
Service & $(0.199)$ & $(0.206)$ & $(0.223)$ \\
& 0.321 & 0.238 & 0.442 \\
Tech. Comp & $(0.185)$ & $(0.171)$ & $(0.154)$ \\
Tech. Non Comp & 0.141 & 0.586 & 0.273 \\
& $(0.150)$ & $(0.272)$ & $(0.208)$ \\
All Occupations & 0.260 & 0.400 & 0.340 \\
& $(0.177)$ & $(0.237)$ & $(0.213)$ \\
\hline & 0.236 & 0.333 & 0.431 \\
& $(0.175)$ & $(0.250)$ & $(0.217)$ \\
\hline
\end{tabular}

Notes: Each cell displays the average, across all individuals working in an occupation, of the portfolio weight of a given human capital type. The standard deviation of the distribution of the portfolio weight across individuals are in parentheses. 
Table 2: Summary Statistics - Selected Variables

\begin{tabular}{cccccc}
\hline & Mean & Median & Std. Dev. & Min. & Max. \\
\hline$\delta$ & 0.276 & 0.238 & 0.164 & 0.018 & 0.848 \\
$\log \left(Y_{91}\right)$ & 8.275 & 8.295 & 0.405 & 6.147 & 9.722 \\
$\Delta Y$ & 0.077 & 0.058 & 0.117 & -0.219 & 0.632 \\
CRED & 124 & 122 & 27 & 80 & 362 \\
WCRED & 259.3 & 225.6 & 108.6 & 104.9 & 849.6 \\
STAY & 0.620 & 1.000 & 0.486 & 0.000 & 1.000 \\
\hline
\end{tabular}

Notes: Before computing growth rates, we deflated earnings by the Consumer Price Index for the appropriate year.

\section{Correlation Matrix - Selected Variables}

\begin{tabular}{ccccccc}
\hline & $\delta$ & $\log \left(Y_{91}\right)$ & $\Delta Y$ & CRED & WCRED & STAY \\
\hline$\delta$ & 1.000 & $-0.040^{*}$ & -0.003 & $0.114^{* *}$ & $0.270^{* *}$ & -0.054 \\
$\log \left(Y_{91}\right)$ & & 1.000 & $0.353^{* *}$ & $0.159^{* *}$ & $0.117^{* *}$ & 0.057 \\
$\Delta Y$ & & & 1.000 & 0.008 & -0.013 & $0.149^{* *}$ \\
CRED & & & & 1.000 & $0.770^{* *}$ & $0.076^{*}$ \\
WCRED & & & & & 1.000 & $0.095^{* *}$ \\
STAY & & & & & & 1.000 \\
\hline
\end{tabular}

Notes: *: Correlation is significant at least at the 0.05 level. ${ }^{* *}$ : Correlation is significant at least at the 0.01 level. 
Table 3: OLS Regression Results - Dependent Variable is $\log \left(Y_{91}\right)$

\begin{tabular}{|c|c|c|c|c|}
\hline & (1) & $\begin{array}{c}\text { Coeff. } \\
(p-v a l .) \\
(2)\end{array}$ & (3) & $(4)$ \\
\hline $\log \left(Y_{1}\right)$ & $\begin{array}{c}0.506 \\
(\text { nil) }\end{array}$ & $\begin{array}{c}0.516 \\
(\text { nil })\end{array}$ & $\begin{array}{c}0.504 \\
\text { (nil) }\end{array}$ & $\begin{array}{c}0.502 \\
(\text { nil })\end{array}$ \\
\hline $\log (C R E D)$ & $\begin{array}{l}0.052 \\
(0.096)\end{array}$ & $\begin{array}{c}0.058 \\
(0.065)\end{array}$ & $\begin{array}{l}0.061 \\
(0.050)\end{array}$ & $\begin{array}{l}0.056 \\
(0.071)\end{array}$ \\
\hline SEX & $\begin{array}{c}-0.091 \\
\left(6.8 \times 10^{-5}\right)\end{array}$ & $\begin{array}{c}-0.092 \\
\left(6.0 \times 10^{-5}\right)\end{array}$ & $\begin{array}{c}-0.094 \\
\left(3.5 \times 10^{-5}\right)\end{array}$ & $\begin{array}{c}-0.092 \\
\left(4.9 \times 10^{-5}\right)\end{array}$ \\
\hline$\delta$ & $\begin{array}{l}-0.079 \\
(0.242)\end{array}$ & $\begin{array}{l}-0.089 \\
(0.186)\end{array}$ & $\begin{array}{l}-0.063 \\
(0.344)\end{array}$ & $\begin{array}{l}0.164 \\
(0.115)\end{array}$ \\
\hline STAY & & $\begin{array}{l}-0.052 \\
(0.026)\end{array}$ & $\begin{array}{c}-7.1 \times 10^{-4} \\
(0.978)\end{array}$ & $\begin{array}{l}0.112 \\
(0.018)\end{array}$ \\
\hline CAREER & & & $\begin{array}{c}0.164 \\
\left(-3.1 \times 10^{-5}\right)\end{array}$ & $\begin{array}{c}0.178 \\
\left(6.8 \times 10^{-6}\right)\end{array}$ \\
\hline$\delta \times S T A Y$ & & & & $\begin{array}{l}-0.379 \\
(0.004)\end{array}$ \\
\hline Intercept & $\begin{array}{l}4.097 \\
\text { (nil) }\end{array}$ & $\begin{array}{l}4.019 \\
(\text { nil) }\end{array}$ & $\begin{array}{l}4.045 \\
(\text { nil ) }\end{array}$ & $\begin{array}{c}4.015 \\
\text { (nil) }\end{array}$ \\
\hline $\begin{array}{l}N \\
R^{2}\end{array}$ & $\begin{array}{c}880 \\
0.347\end{array}$ & $\begin{array}{c}880 \\
0.353\end{array}$ & $\begin{array}{c}880 \\
0.366\end{array}$ & $\begin{array}{c}880 \\
0.372\end{array}$ \\
\hline
\end{tabular}

Notes: CAREER equals one if an individual begins her labor market experience in a nonmanagerial occupation and ends in a managerial occupation. 
Table 4: Probit Regression - Dependent Variable : STAY

\begin{tabular}{lcccc}
\hline \multicolumn{5}{c}{ Coefficient Estimate } \\
& $(1)$ & $(2)$ & $(3)$ & $(4)$ \\
\hline$\delta$ & -0.402 & -0.371 & -0.555 & -0.419 \\
& $(0.112)$ & $(0.149)$ & $(0.038)$ & $(0.098)$ \\
$\log \left(Y_{1}\right)$ & & 0.540 & 0.521 & 0.483 \\
& & $\left(-1.1 \times 10^{-7}\right)$ & $\left(-3.2 \times 10^{-7}\right)$ & $($ nil $)$ \\
$\log (C R E D)$ & & & 0.339 & 0.279 \\
& & & $(0.007)$ & $(0.183)$ \\
SEX & & & & -0.028 \\
& & & & $(0.755)$ \\
Intercept & 0.417 & -3.915 & -5.563 & -5.458 \\
& $\left(-5.6 \times 10^{-7}\right)$ & $\left(-1.8 \times 10^{-6}\right)$ & $($ nil $)$ & $\left(-6.0 \times 10^{-7}\right)$ \\
\hline
\end{tabular}

Notes: The table displays the coefficients of four alternative specifications of a Probit model with STAY as the dependent variable. 
Table 5: Elements of the Vector $\hat{Y}$

\begin{tabular}{lcccc}
\hline Occupation & Sample Size & $\omega_{H}$ & $\omega_{Q}$ & $\%$ Switch \\
\hline Clerical & 150 & $0.264(0.017)$ & $0.269(0.019)$ & $0.222(0.015)$ \\
Manager & 260 & $0.221(0.010)$ & $0.289(0.014)$ & $0.155(0.008)$ \\
Skilled Op. & 20 & $0.181(0.026)$ & $0.497(0.079)$ & $0.250(0.057)$ \\
Prof. Arts & 30 & $0.492(0.037)$ & $0.132(0.015)$ & $0.189(0.027)$ \\
Prof- Medical & 50 & $0.226(0.018)$ & $0.433(0.032)$ & $0.048(0.007)$ \\
Prof - Engineer & 40 & $0.098(0.012)$ & $0.760(0.024)$ & $0.051(0.008)$ \\
Prof - Other & 120 & $0.231(0.016)$ & $0.281(0.018)$ & $0.102(0.009)$ \\
Sales & 90 & $0.244(0.015)$ & $0.239(0.016)$ & $0.202(0.018)$ \\
School Teacher & 40 & $0.330(0.032)$ & $0.285(0.033)$ & $0.212(0.028)$ \\
Service & 10 & $0.321(0.062)$ & $0.238(0.057)$ & $0.529(0.088)$ \\
Tech. Comp. & 80 & $0.141(0.017)$ & $0.586(0.031)$ & $0.152(0.015)$ \\
Tech. Non Comp. & 20 & $0.260(0.044)$ & $0.400(0.059)$ & $0.263(0.051)$ \\
\hline & Sample Size & & & \\
\hline Standard Deviation $($ Log) Earnings & & & & \\
First Period & 860 & $0.438(0.011)$ & & \\
Standard Deviation $\omega_{H}$ & 860 & $0.176(0.004)$ & & \\
Standard Deviation $\omega_{Q}$ & 860 & $0.251(0.006)$ & & \\
Standard Deviation $\omega_{S S}$ & 860 & $0.218(0.005)$ & & \\
\% “Stay-Switch Events” & 860 & $0.088(0.002)$ & & \\
$\rho\left(C R E D_{S S}, C R E D_{Q}\right)$ & 860 & $-0.151(0.033)$ & & \\
$\rho\left(C R E D_{S S}, C R E D_{H}\right)$ & 860 & $-0.047(0.034)$ & & \\
$\rho\left(C R E D_{H}, C R E D_{Q}\right)$ & 860 & $-0.401(0.029)$ & & \\
\hline Nof E & & & & \\
\hline
\end{tabular}

Notes: Each cell reports a sample moment, either a mean or a standard deviation, and in parentheses an estimate of the standard deviation of that sample moment. In the upper panel we report, for each occupation, the mean portfolio shares in Humanities and Quantitative Skills, and the fraction of Switchers in the first period. In the lower panel, we report the standard deviations of (Log) Earnings in the initial period, the cross-sectional standard deviation for the portfolio shares in each skill type, the fraction of "Stay-Switch Events" (see main text for an explanation of how the statistic is computed) and the cross-sectional correlations among the different human capital types. We also report the sample size used to compute each sample moment. 
Table 6: Estimation Results

\begin{tabular}{lccc}
\hline Occupation & $\hat{\alpha}_{H}$ & $\hat{\alpha}_{Q}$ & $\hat{\sigma}_{\epsilon}$ \\
\hline Clerical & $0.182(0.028)$ & $0.441(0.027)$ & $0.161(0.055)$ \\
Manager & $0.156(0.038)$ & $0.405(0.112)$ & $0.088(0.027)$ \\
Skilled Op. & $0.145(0.078)$ & $0.738(0.014)$ & $0.221(0.092)$ \\
Prof. Arts & $0.687(0.018)$ & $0.153(0.021)$ & $0.387(0.016)$ \\
Prof- Medical & $0.136(0.049)$ & $0.664(0.157)$ & $0.075(0.014)$ \\
Prof - Engineer & $0.038(0.020)$ & $0.918(0.078)$ & $0.210(0.067)$ \\
Prof - Other & $0.140(0.007)$ & $0.478(0.024)$ & $0.102(0.291)$ \\
Sales & $0.162(0.007)$ & $0.464(0.048)$ & $0.170(0.132)$ \\
School Teacher & $0.228(0.038)$ & $0.428(0.056)$ & $0.167(0.012)$ \\
Service & $0.307(0.121)$ & $0.424(0.015)$ & $0.415(0.130)$ \\
Tech. Comp. & $0.111(0.161)$ & $0.792(0.116)$ & $0.149(0.022)$ \\
Tech. Non Comp. & $0.180(0.058)$ & $0.664(0.029)$ & $0.174(0.144)$ \\
\hline \multicolumn{5}{c}{ Estimate $($ Std. Error $)$} & & \\
\hline$\sigma_{\theta}$ & $0.258(0.052)$ & & \\
$\sigma_{\xi_{H}}^{2}$ & $0.933(0.030)$ & & \\
$\sigma_{\xi_{Q}}^{2}$ & $0.217(0.009)$ & & \\
$\sigma_{\xi_{S S}}^{2}$ & $1.811(0.042)$ & & \\
$\pi$ & $0.861(0.042)$ & & \\
$\rho_{\tilde{\xi}}$ & $-0.254(0.042)$ & & \\
\hline
\end{tabular}

Notes: This table reports the estimated value for each element in $\Lambda$, the vector of structural parameters. In parenthesis, we report numerical standard errors computed using (1). 
Table 7: Income Growth Distribution Summary - Model vs.

Data

\begin{tabular}{lccccc}
\hline & Min. & 1st. Quart. & Median & Mean & 3rd Quart. \\
\hline Data & -0.219 & 0.0139 & 0.0577 & 0.0774 & 0.1184 \\
Model & -0.1562 & 0.0296 & 0.0651 & 0.0715 & 0.1030 \\
\hline
\end{tabular}

\begin{tabular}{lcccc}
\hline & Max. & Std. Dev. & Skew. & Kurt. \\
\hline Data & 0.6315 & 0.1159 & 1.2421 & 6.1649 \\
Model & 0.4908 & 0.0653 & 0.8980 & 5.4849 \\
\hline
\end{tabular}

Notes: The table compares some moments in the income growth distribution from the HS\&B dataset with a model-simulated (9,000 individuals) income growth distribution. The sample of students used to compute the Data moments are the same 950 individuals reported in Table 5.

Table 8: Regression Results - Model-Simulated Final Wage $\left(\log \left(Y_{91}\right)\right)$

\begin{tabular}{lcccc}
\hline \multicolumn{5}{c}{$\begin{array}{c}\text { Coefficient Estimate } \\
(p-v a l .)\end{array}$} \\
& $(1)$ & $(2)$ & $(3)$ & $(4)$ \\
\hline $\log \left(Y_{1}\right)$ & 0.826 & 0.739 & 0.506 & 0.502 \\
& $($ nil $)$ & $($ nil $)$ & $($ nil $)$ & $($ nil $)$ \\
$\log ($ CRED $)$ & 0.119 & 0.184 & 0.052 & 0.056 \\
& $($ nil $)$ & $($ nil $)$ & $(0.096)$ & $(0.071)$ \\
$\delta$ & -0.022 & 0.082 & -0.079 & 0.164 \\
& $(0.436)$ & $(0.0789)$ & $(0.242)$ & $(0.115)$ \\
STAY & & 0.277 & & 0.112 \\
& & $($ nil $)$ & & $0.018)$ \\
$\delta \times S T A Y$ & & -0.135 & & -0.379 \\
& & $(0.011)$ & & $(0.004)$ \\
Intercept & 0.309 & 0.101 & 4.097 & 4.015 \\
& $($ nil $)$ & $($ nil $)$ & $($ nil $)$ & $($ nil $)$ \\
\hline$N$ & 9,000 & 9,000 & 880 & 880 \\
$R^{2}$ & 0.751 & 0.799 & 0.347 & 0.303 \\
\hline
\end{tabular}

Notes: The first two columns of the table shows results from regressing income growth $(\Delta Y)$ on the variables shown in column 1 for the sample of individuals. The last two columns replicate Columns 2 and 4 in Table 3 to ease the comparison between data and model. 
Table 9: Probit Regression Results - Model-Simulated Occupational Stayers vs. Switchers (STAY)

\begin{tabular}{|c|c|c|c|c|}
\hline \multicolumn{5}{|c|}{$\begin{array}{c}\text { Coefficient Estimate } \\
(p-v a l .)\end{array}$} \\
\hline & $(1)$ & $(2)$ & $(3)$ & (4) \\
\hline \multirow[t]{2}{*}{$\delta$} & -0.956 & -0.909 & -0.402 & -0.419 \\
\hline & (nil) & (nil) & $(0.112)$ & (0.098) \\
\hline \multirow[t]{2}{*}{$\log \left(Y_{1}\right)$} & & 0.585 & & 0.483 \\
\hline & & (nil) & & (nil) \\
\hline \multirow[t]{2}{*}{ Intercept } & 0.918 & -0.095 & 0.417 & -5.458 \\
\hline & (nil) & $(0.001)$ & $\left(-5.6 \times 10^{-7}\right)$ & $\left(-6.0 \times 10^{-7}\right)$ \\
\hline$N$ & 9,000 & 9,000 & 880 & 880 \\
\hline
\end{tabular}

Table 10: Baseline and Counterfactual Earnings Distributions: Cobb-Douglas Payoffs

\begin{tabular}{rcccccc}
\hline & \multicolumn{3}{c}{ Baseline } & \multicolumn{3}{c}{ Counterfactual } \\
& $\mathbb{E}(\Delta Y)$ & $\sigma\left(\log \left(Y_{91}\right)\right)$ & $\%$ Switchers & $\mathbb{E}(\Delta Y)$ & $\sigma\left(\log \left(Y_{91}\right)\right)$ & $\%$ Switchers \\
\hline All & 0.0715 & 0.4647 & 22.5 & -10.35 & -0.1 & -12.90 \\
Switchers & 0.0279 & 0.3935 & & -38.96 & 1.93 & \\
Non-Switch. & 0.0835 & 0.4410 & & -5.65 & -0.52 & \\
\hline
\end{tabular}

Notes: The left-side panel (first three columns) reports moments of the baseline earnings distribution. The right-side panel (last three columns) summarizes the earnings distribution when agents are forced to specialize as described in the text. Both model-generated distributions come from the same cross-section of 9,000 individuals. 
Table 11: Counterfactual Earnings Distributions: CES Payoffs

\begin{tabular}{|c|c|c|c|c|c|c|}
\hline & \multicolumn{3}{|c|}{$\rho=-0.15$} & \multicolumn{3}{|c|}{$\rho=-1.15$} \\
\hline & $\mathbb{E}(\Delta y)$ & $\sigma\left(\log \left(y_{1991}\right)\right)$ & $\%$ Switch. & $\mathbb{E}(\Delta y)$ & $\sigma\left(\log \left(y_{1991}\right)\right)$ & $\%$ Switch \\
\hline $\begin{array}{r}\text { Optimal } \\
\text { Specialization }\end{array}$ & & & & & & \\
\hline All & -2.64 & -0.69 & -13.10 & -6.13 & -1.74 & -14.09 \\
\hline Switchers & -28.24 & -4.74 & & -26.33 & -1.36 & \\
\hline Non-Switch. & -2.23 & -0.88 & & -6.57 & -2.25 & \\
\hline
\end{tabular}

Notes: The table reports the percentage changes when the same 9,000 individuals in the cross-section are forced to specialize as described in the text. The percentage changes are calculated relative to the unrestricted-portfolio case when the elasticity of substitution between human capital types is given by $\frac{1}{1-\rho}$ for $\rho=-0.15$ and $\rho=-1.25$.

\section{A Appendix (For Online Publication)}

\section{A.1 Data}

Merging the PETS and Sophomores in 1980 - HS\&B datasets yields an initial sample of 8,395 students. Dropping those who do not have an associates degree or who have a doctorate / advanced professional degree (doctors and lawyers, primarily) eliminates 3,637 individuals. Deleting those with missing data on earnings, employment status, or occupation reduces the sample to 2,499 individuals.

To account for possible unemployment spells which may distort measures of annual earnings, dividing annual earnings by number of months employed yields monthly earnings for all years in the sample, 1986-1991. Individuals reporting negative or zero monthly earnings for a given year are dropped as are individuals who report working in one of the following occupations: farmer, laborer, protective services, and the military.

To find portfolios, human capital is partitioned into three broad areas of knowledge: Quantitative (Q), Social Sciences (SS), and Humanities (H). Each of these areas is the sum of credits taken in areas of study belonging to that area of knowledge.

- $\mathrm{Q}=$ Non-Additive Pre-College Level Math+Credits in College-Level Math + Cred- 
its in Calculus and Advanced Math+ Other Math Credits from Math Depts.+ Credits in all Statistics Courses + Credits in Science + Credits in Engineering + Credits in Computer Science + Credits in Computer-Related Courses

- $\mathrm{H}=$ Total Credits in Humanities Courses + Total Credits in Arts and Performing Arts.

- $\mathrm{SS}=$ Total Credits in Business Courses + Total Social Science Credits + Credits in Basic Communications Courses

Students with less than 80 credits or those who report missing values for credits in any of the four categories are dropped. ${ }^{27}$

This procedure reduces the sample to 1,360 students with complete labor market histories - average earnings per month and occupation for given year - plus a description of their human capital investments. The total number of credits in the three areas of knowledge (and consequently the vector of portfolio weights $\omega$ ) summarize these human capital investments.

The year of graduation further reduces the sample. Students who graduated in either 1988, 1989, 1990, or 1991 are dropped because despite reporting labor market histories, from the perspective of the model those histories are irrelevant. In the model, we analyze histories after investing in human capital and therefore discard labor market histories contemporaneous to those human capital investments. Discarding such histories leaves a total of 920 students.

The OLS regressions reported in Table 3 in Section 2 use a truncated sample of 880 students; students in the bottom and top 2 percentiles in the earnings growth distribution are dropped.

\footnotetext{
${ }^{27}$ The PETS dataset provides no direction on what subjects exactly constitute each of the definitions included in the main four areas of knowledge. They provide a definition for each of the variables used to avoid the double-counting of credits as much as possible. For instance, in the categories of humanities credits, they include Foreign Languages, but they report as a separate category credits in Foreign Languages.
} 
Students who become workers are grouped into broader occupation categories than those defined in the original HS\&B dataset. For example, in the original HS\&B there are four categories of managers, three categories for owners, and three categories for clerical workers. We group them all into "Managerial", "Owner", and "Clerical" categories. This aggregation reduces the number of occupations (increases the sample size and therefore decrease the degree of sampling error) in the empirical analysis.

Finally, because the Sophomores of 1980 data set is not as widely used in the economics literature as other panels such as the PSID, NLSY, or SIPP, we compare the unconditional distribution of income by year from HS\&B with Current Population Survey (CPS) data. Figure A-1 displays kernel-smoothed estimates of the annual (nominal) earnings distribution from the CPS and the HS\&B. Since the objective is to assess the overall quality of the survey, the figure includes all respondents, not just the subsample of relatively-higher educated individuals. To get the appropriate population in the CPS we restricted it to those respondents having roughly the same age as the respondents in the HS\&B. The figure illustrates that except for the lower levels of earnings in 1986 and 1987, the two distributions are comparable for the remaining years. If

anything, it seems as if the CPS shows a large mass of individuals with unreasonably low levels of annual earnings.

\section{A.2 Model Solution and Estimation}

Given a value for the structural vector of parameters $\Lambda$, the following algorithm describes the solution of the model described in the text.

- For a given individual, draw a vector $\boldsymbol{\theta}$ (productivity signals) and $\xi$ (abilities).

- For a given value of the portfolio $\boldsymbol{h}$, compute the cost function $\mathcal{C}(\boldsymbol{h}, \xi)$.

- To compute the expected value in the labor market, proceed as follows: 
- Compute initial Gittins indices $\left\{M_{j}(\boldsymbol{\theta}, \boldsymbol{h}, \varnothing)\right\}$. The indices provide a ranking initial occupational choices. Standard integration routines are used to compute the indices.

- For $t=2, T$, (where $T=100)$ simulate an individual's labor market history by (a) sampling a uniform random variable; learning takes place when the draw is larger than $\pi$ and, (b) updating the productivity values by sampling from the appropriate log-normal distribution. This labor market history provides a discounted value of earnings.

- Repeat the previous step $N_{H}=500$ times, yielding $N_{H}$ possible labor market histories.

- The expected value of an individual in the labor market is given by the average of the $N_{H}$ labor market histories appropriately discounted.

- Find the optimal portfolio by maximizing the difference between expected labor market earnings and the cost.

- Using a random draw from a uniform distribution, sample a labor market history (occupations and earnings).

These steps determine the optimal portfolio and a sequence of earnings and occupational transitions for a given individual $i$. Repeating the same steps (independently) for a large cross-section of individuals (the number used in the estimation is 9,000 individuals) yields a distribution of earnings, growth rates of earnings, occupational choices and optimal portfolios.

This distribution provides the elements of the vector $\hat{Y}$. A typical element of that vector is a statistic from that distribution of a panel of individuals. We use a NelderMead algorithm to find the minimizer $\hat{\Lambda}$ of the criterion function (A-1).

$$
\hat{\Lambda}=\underset{\Lambda}{\operatorname{argmin}}(\mathrm{Y}-\hat{\mathrm{Y}})^{\prime}(\mathrm{Y}-\hat{\mathrm{Y}})
$$


We use forward-difference numerical differentiation to compute the Jacobian matrix of the criterion function. After finding the Jacobian, evaluating (1) is straightforward.

\section{A.3 Additional Results}

The following two tables display the same least-squares regressions as those shown in Tables 3 and 4 (i.e. the baseline regression with 1991 income as the lef-hand side variable and the Probit regression with STAY as the left-hand side variable). The only difference pertains to the number of human capital types. Instead of lumping the category "Fine and Other Performing Arts" credits into Humanities, here we consider

those two types as separate categories. As a result, the number of types is $K=4$. Given the results are quantitatively similar to the case where $K=3$, the conclusions and inferences drawn in the main text carry over to this specification. 
Table 12: OLS Regression Results - Dependent Variable is

\begin{tabular}{|c|c|c|c|c|}
\hline & (1) & $\begin{array}{c}\text { Coeff. } \\
(p \text {-val. }) \\
(2)\end{array}$ & (3) & (4) \\
\hline $\log \left(Y_{1}\right)$ & $\begin{array}{c}0.504 \\
\text { (nil) }\end{array}$ & $\begin{array}{c}0.514 \\
(\text { nil })\end{array}$ & $\begin{array}{c}0.502 \\
\text { (nil) }\end{array}$ & $\begin{array}{c}0.500 \\
\text { (nil) }\end{array}$ \\
\hline $\log (C R E D)$ & $\begin{array}{l}0.131 \\
(0.021)\end{array}$ & $\begin{array}{c}0.137 \\
(0.014)\end{array}$ & $\begin{array}{l}0.128 \\
(0.022)\end{array}$ & $\begin{array}{l}0.118 \\
(0.033\end{array}$ \\
\hline SEX & $\begin{array}{c}-0.083 \\
\left(3.7 \times 10^{-4}\right)\end{array}$ & $\begin{array}{c}-0.083 \\
\left(3.5 \times 10^{-4}\right)\end{array}$ & $\begin{array}{c}-0.086 \\
\left(1.8 \times 10^{-4}\right)\end{array}$ & $\begin{array}{c}-0.084 \\
\left(2.5 \times 10^{-4}\right)\end{array}$ \\
\hline$\delta$ & $\begin{array}{r}-0.055 \\
(0.393)\end{array}$ & $\begin{array}{l}-0.062 \\
(0.333)\end{array}$ & $\begin{array}{l}-0.035 \\
(0.582)\end{array}$ & $\begin{array}{c}0.194 \\
(0.054)\end{array}$ \\
\hline STAY & & $\begin{array}{l}-0.051 \\
(0.026)\end{array}$ & $\begin{array}{l}-0.001 \\
(0.959)\end{array}$ & $\begin{array}{l}0.114 \\
(0.015)\end{array}$ \\
\hline CAREER & & & $\begin{array}{c}0.159 \\
\left(-5.5 \times 10^{-5}\right)\end{array}$ & $\begin{array}{c}0.174 \\
\left(1.1 \times 10^{-5}\right)\end{array}$ \\
\hline$\delta \times S T A Y$ & & & & $\begin{array}{l}-0.385 \\
(0.003)\end{array}$ \\
\hline Intercept & $\begin{array}{c}3.757 \\
\text { (nil) }\end{array}$ & $\begin{array}{c}3.677 \\
\text { (nil) }\end{array}$ & $\begin{array}{c}3.760 \\
\text { (nil) }\end{array}$ & $\begin{array}{c}3.744 \\
\text { (nil) } \\
\end{array}$ \\
\hline $\begin{array}{l}N \\
R^{2}\end{array}$ & $\begin{array}{c}880 \\
0351\end{array}$ & $\begin{array}{c}880 \\
0355\end{array}$ & $\begin{array}{c}880 \\
0367\end{array}$ & $\begin{array}{c}880 \\
0373\end{array}$ \\
\hline
\end{tabular}

Notes: CAREER equals one if an individual begins her labor market experience in a nonmanagerial occupation and ends in a managerial occupation. 
Table 13: Probit Regression - Dependent Variable : STAY

\begin{tabular}{lcccc}
\hline \multicolumn{5}{c}{ Coefficient Estimate } \\
& $(1)$ & $(2)$ & $(3)$ & $(4)$ \\
\hline$\delta$ & -0.393 & -0.351 & -0.387 & -0.386 \\
& $(0.114)$ & $(0.165)$ & $(0.129)$ & $(0.131)$ \\
$\log \left(Y_{1}\right)$ & & 0.539 & 0.517 & 0.515 \\
& & $\left(-1.1 \times 10^{-7}\right)$ & $\left(-4.3 \times 10^{-7}\right)$ & $($ nil $)$ \\
$\log (C R E D)$ & & & 0.394 & 0.386 \\
& & & $(0.072)$ & $(0.085)$ \\
SEX & & & & -0.014 \\
& & & & $(0.878)$ \\
Intercept & 0.416 & -3.913 & -5.612 & -5.535 \\
& $\left(-5.6 \times 10^{-7}\right)$ & $\left(-1.8 \times 10^{-6}\right)$ & $\left(-7.1 \times 10^{-6}\right)$ & $\left(-4.0 \times 10^{-5}\right)$ \\
\hline
\end{tabular}

Notes: The table displays the coefficients of four alternative specifications of a Probit model with STAY as the dependent variable.
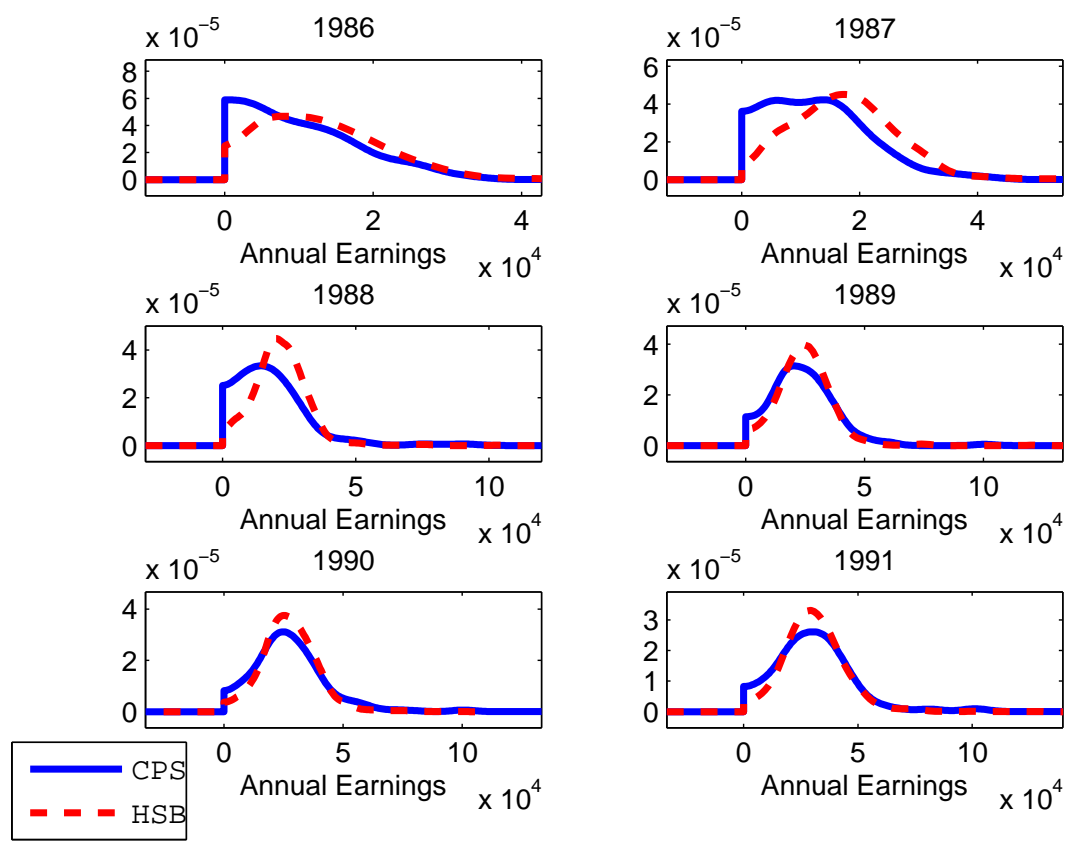

Figure A-1: Comparison of unconditional annual earnings distributions in the CPS and the HS\&B. 